\title{
Review Article \\ Honey, Propolis, and Royal Jelly: A Comprehensive Review of Their Biological Actions and Health Benefits
}

\author{
Visweswara Rao Pasupuleti, ${ }^{1,2}$ Lakhsmi Sammugam, ${ }^{2}$ Nagesvari Ramesh, ${ }^{2}$ and \\ Siew Hua Gan ${ }^{3}$ \\ ${ }^{1}$ Institute of Food Security and Sustainable Agriculture, Universiti Malaysia Kelantan, Campus Jeli, 17600 Jeli, Malaysia \\ ${ }^{2}$ Faculty of Agro-Based Industry, Universiti Malaysia Kelantan, Campus Jeli, 17600 Jeli, Malaysia \\ ${ }^{3}$ Human Genome Center, School of Medical Sciences, Universiti Sains Malaysia, Kubang Kerian, 16150 Kelantan, Malaysia
}

Correspondence should be addressed to Visweswara Rao Pasupuleti; visuthebiotech@gmail.com

Received 17 February 2017; Accepted 9 April 2017; Published 26 July 2017

Academic Editor: Jasminka Giacometti

Copyright (c) 2017 Visweswara Rao Pasupuleti et al. This is an open access article distributed under the Creative Commons Attribution License, which permits unrestricted use, distribution, and reproduction in any medium, provided the original work is properly cited.

\begin{abstract}
Background. There are several health benefits that honeybee products such as honey, propolis, and royal jelly claim toward various types of diseases in addition to being food. Scope and Approach. In this paper, the effects of honey, propolis, and royal jelly on different metabolic diseases, cancers, and other diseases have been reviewed. The modes of actions of these products have also been illustrated for purposes of better understanding. Key Findings and Conclusions. An overview of honey, propolis, and royal jelly and their biological potentials was highlighted. The potential health benefits of honey, such as microbial inhibition, wound healing, and its effects on other diseases, are described. Propolis has been reported to have various health benefits related to gastrointestinal disorders, allergies, and gynecological, oral, and dermatological problems. Royal jelly is well known for its protective effects on reproductive health, neurodegenerative disorders, wound healing, and aging. Nevertheless, the exact mechanisms of action of honey, propolis, and royal jelly on the abovementioned diseases and activities have not been not fully elucidated, and further research is warranted to explain their exact contributions.
\end{abstract}

\section{Introduction}

Apiculture is the science and art of prolonging, sustaining, and retaining health by using products obtained from honeybee hives, such as honey, bee bread, bee venom, bee pollen, propolis, and royal jelly. Recent years have seen the fast application of bee products in both traditional and modern medicine. Currently, many studies are targeted toward investigating directed health benefits and pharmacological properties of bee products due to their efficacies, leading to the increasing development of nutraceuticals and functional food from these products. The concept of functional food refers to food that has the ability to promote better physiological or psychological health compared to traditional remediated and nutritional food. These effects positively contribute toward excellent health maintenance, well-being, and reduced chronic illness [1]. The present review focuses on the potential health benefits of bee products, including honey, propolis, and royal jelly.

Honey is a sweet liquid processed by the honey bee. Honey is recognized worldwide due to its high nutritive components that are beneficial for human well-being. It has been traditionally used by Egyptians, Greeks, Romans, and Chinese to heal wounds and diseases of the gut, including gastric ulcers. It has also been used as a remedy for cough, sore throat, and earaches [2]. In India, Lotus honey has been traditionally used to treat eye infections and other diseases. In addition to being used externally, honey is also used internally [3] as a functional food to provide energy and nourishment to enhance vital organs in the body [4]. This has been in practice since ancient times. The active components of honey, such as glucose, fructose, flavonoid, polyphenols, and organic acids, play an important role in its quality [5]. Honey is being produced in many countries all over the 
world and is recognized as an important medicine as well as energy-providing food due to its functional properties and nutritional values. Additionally, honey is well known for its biological, physiological, and pharmacological activities.

Propolis is generally known as the "bee glue", which is a generic name that refers to the resinous substance accumulated by the bees from different types of plants. The word "propolis" is derived from Greek to mean defense for "pro" and city or community for "polis", or the beehive, in other words [6]. Propolis functions in sealing holes and cracks and for the reconstruction of the beehive. It is also used for smoothing the inner surface of the beehive, retaining the hive's internal temperature $\left(35^{\circ} \mathrm{C}\right)$, preventing weathering and invasion by predators. Furthermore, propolis hardens the cell wall and contributes to an aseptic internal environment. Propolis generally becomes soft and sticky upon heating [7]. It also possesses a pleasant smell. Propolis and its extracts have numerous applications in treating various diseases due to its antiseptic, anti-inflammatory, antioxidant, antibacterial, antimycotic, antifungal, antiulcer, anticancer, and immunomodulatory properties.

Royal jelly, a white and viscous jelly-like substance, is a form of hypopharyngeal and mandibular gland secretion from the worker bees. It is also known as a "superfood" that is solely consumed by the queen bee. Royal jelly is also fed to the honeybee larvae upon hatching and helps to nurture the brood [8]. It is the exclusive nutriment offered to the immature young larvae in their first 2-3 days of maturation besides being used as a food specifically for the queen bee throughout her entire life cycle. Royalactin is the main compound in royal jelly that allows the morphological change of a larva into the queen bee [9]. This superfood is the main reason for the longevity of the queen bee compared to the other bees. Royal jelly is widely used as a dietary nutritional complex to help combat various chronic health conditions. Furthermore, it is one of the profitable remedies for human beings in both traditional and modern medicine. Many pharmacological activities such as antibacterial, antitumor, antiallergy, antiinflammatory, and immunomodulatory effects have also been attributed to it.

\section{Chemical Composition of Honey, Propolis, and Royal Jelly}

Honey is also known as a supersaturated sugar solution. Natural honey is composed of $82.4 \%$ carbohydrates, $38.5 \%$ fructose, $31 \%$ glucose, $12.9 \%$ other sugars, $17.1 \%$ water, $0.5 \%$ protein, organic acids, multiminerals, amino acids, vitamins, phenols, and a myriad of other minor compounds. In addition, honey consists of minor amounts of bioactive components, including phenolic acid, flavonoid, and $\alpha$-tocopherol [10]. Honey constituents with health benefits include phenolic acids, flavonoids, ascorbic acid, proteins, carotenoids, and certain enzymes, such as glucose oxidase and catalase [11].

Propolis is the third most important component of bee products. It is composed mainly of resin (50\%), wax (30\%), essential oils (10\%), pollen (5\%), and other organic compounds (5\%) [12]. Phenolic compounds, esters, flavonoids, terpenes, beta-steroids, aromatic aldehydes, and alcohols are the important organic compounds present in propolis [13]. Twelve different flavonoids, namely, pinocembrin, acacetin, chrysin, rutin, luteolin, kaempferol, apigenin, myricetin, catechin, naringenin, galangin, and quercetin; two phenolic acids, caffeic acid and cinnamic acid; and one stilbene derivative called resveratrol have been detected in propolis extracts by capillary zone electrophoresis [14]. Propolis also contains important vitamins, such as vitamins B1, B2, $\mathrm{B} 6, \mathrm{C}$, and $\mathrm{E}$ and useful minerals such as magnesium $(\mathrm{Mg})$, calcium $(\mathrm{Ca})$, potassium $(\mathrm{K})$, sodium $(\mathrm{Na})$, copper $(\mathrm{Cu})$, zinc $(\mathrm{Zn})$, manganese $(\mathrm{Mn})$, and iron $(\mathrm{Fe})$. A few enzymes, such as succinic dehydrogenase, glucose-6-phosphatase, adenosine triphosphatase, and acid phosphatase, are also present in propolis [15].

Royal jelly consists of water $(50 \%-60 \%)$, proteins $(18 \%)$, carbohydrates (15\%), lipids (3\%-6\%), mineral salts (1.5\%), and vitamins [16]. Based on modern spectrometric analysis, approximately 185 organic compounds have been detected in royal jelly. Royalactin is the most important protein present in royal jelly. In addition, royal jelly is composed of a significant number of bioactive compounds, including 10-hydroxy-2-decenoic acid (HAD), which has some immunomodulatory properties [17]. Fatty acid, proteins, adenosine monophosphate (AMP) N1 oxide, adenosine, acetylcholine, polyphenols, and hormones such as testosterone, progesterone, prolactin, and estradiol are other useful bioactive components reported to be present in royal jelly [18].

\section{Bioactive Compounds in Honey, Propolis, and Royal Jelly}

Honey, propolis, and royal jelly are highly rich in bioactive compounds (Table 1). Essential and nonessential compounds, such as polyphenols and vitamins occurring naturally as part of food chains, are considered bioactive. These compounds are naturally present in food and confer useful health benefits. Phenolic compounds are bioactive compounds. Phenols are defined as organic compounds with an aromatic ring that is chemically bonded to one or additional hydrogenated substituents in the presence of corresponding functional derivatives [19].

In honey, propolis, and royal jelly, phenolic compounds are commonly present as flavonoids [20]. Various phenolic compounds contribute to the functional properties of bee products, including their antioxidant, antimicrobial, antiviral, anti-inflammatory, antifungal, wound healing, and cardioprotective activities [21]. Figure 1 summarizes the important biological efficacies of bee products.

\section{Health Benefits of Honey}

4.1. Wound Management. Honey has traditionally been used to treat wounds, insect bites, burns, skin disorders, sores, and boils. Scientific documentation of the wound-healing capabilities of honey validates its efficacy as a promoter of wound repair and an antimicrobial agent [37]. Honey promotes the activation of dormant plasminogen in the wound matrix, which results in the dynamic expression of the proteolytic 


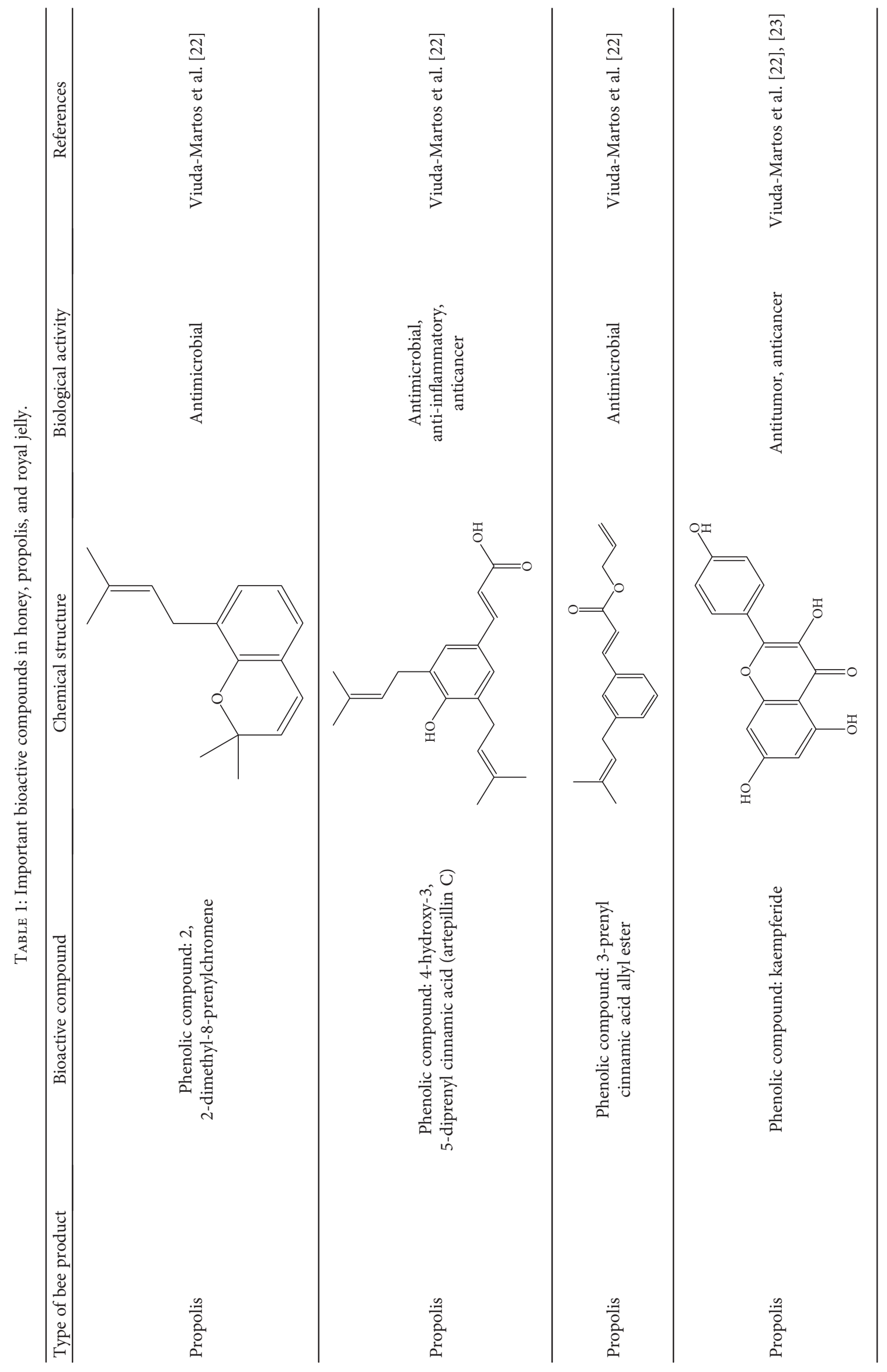




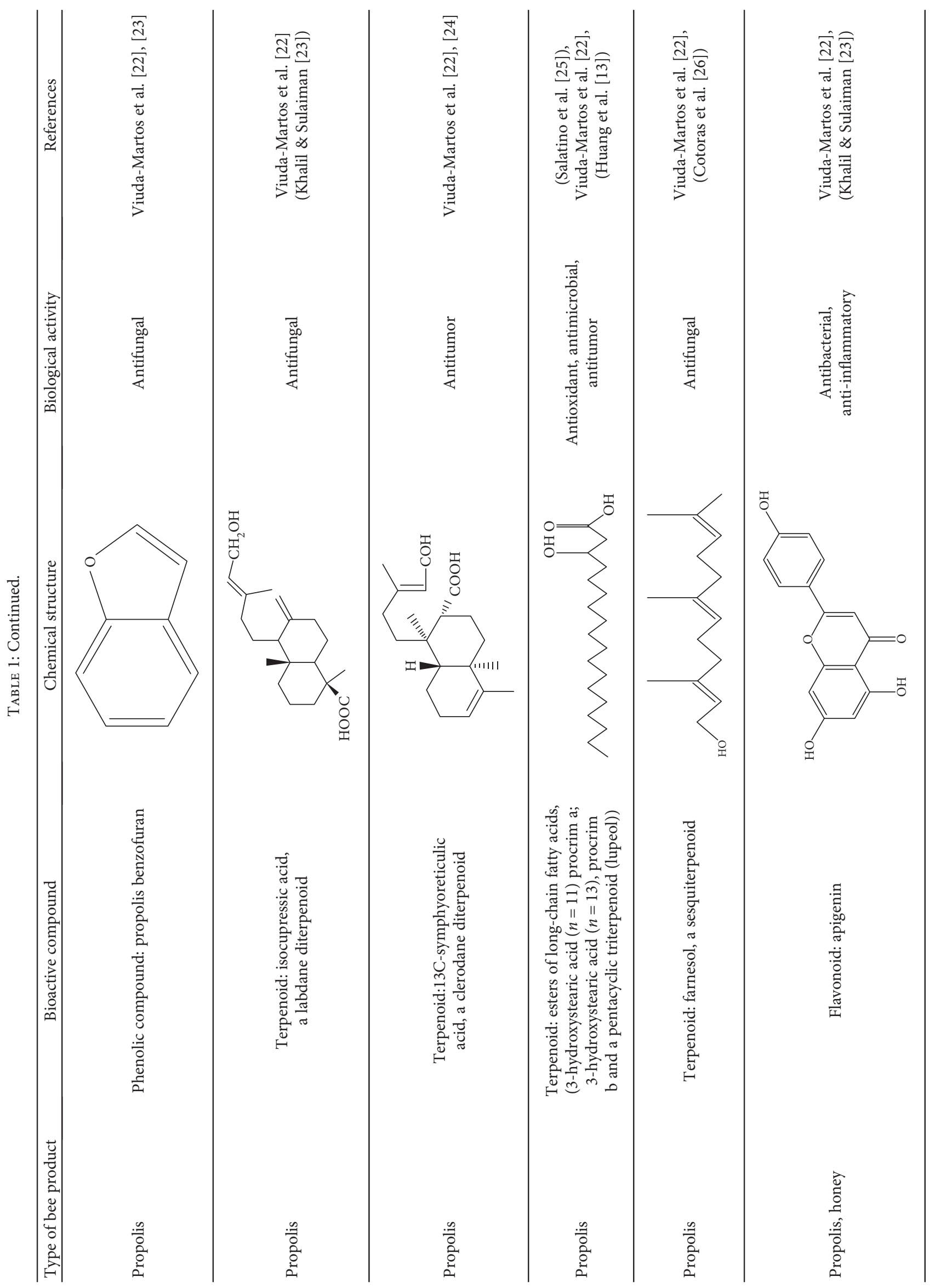




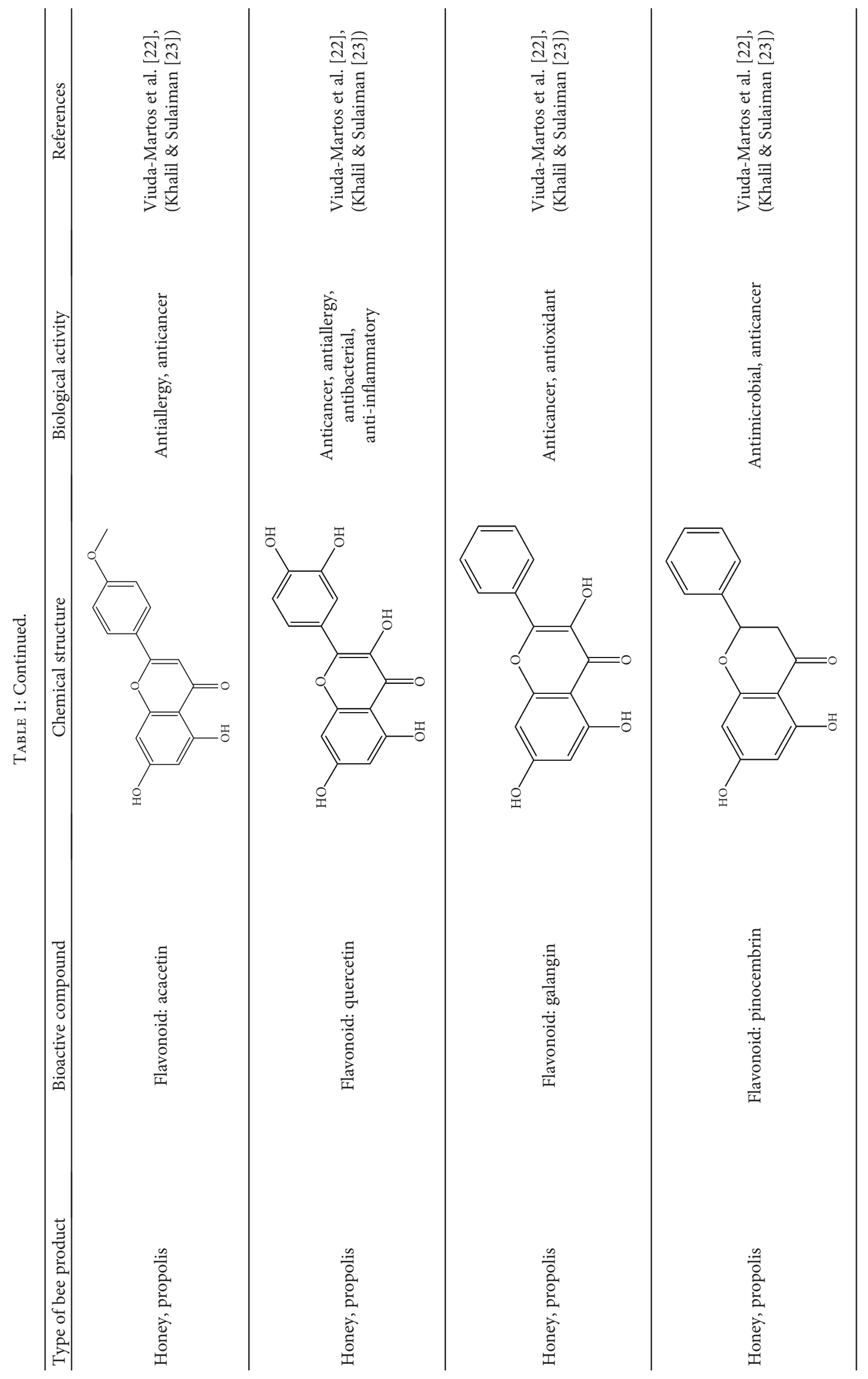




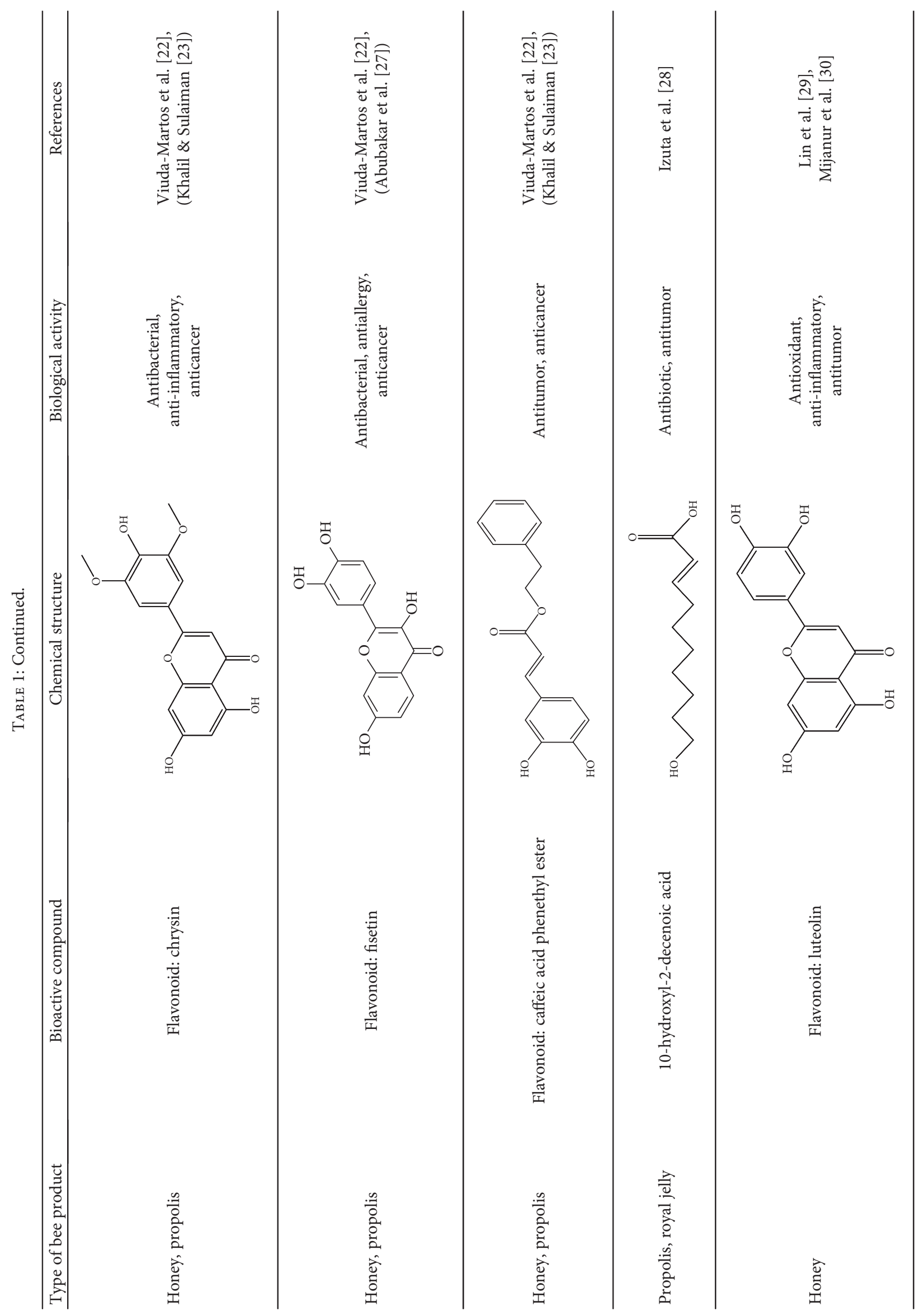




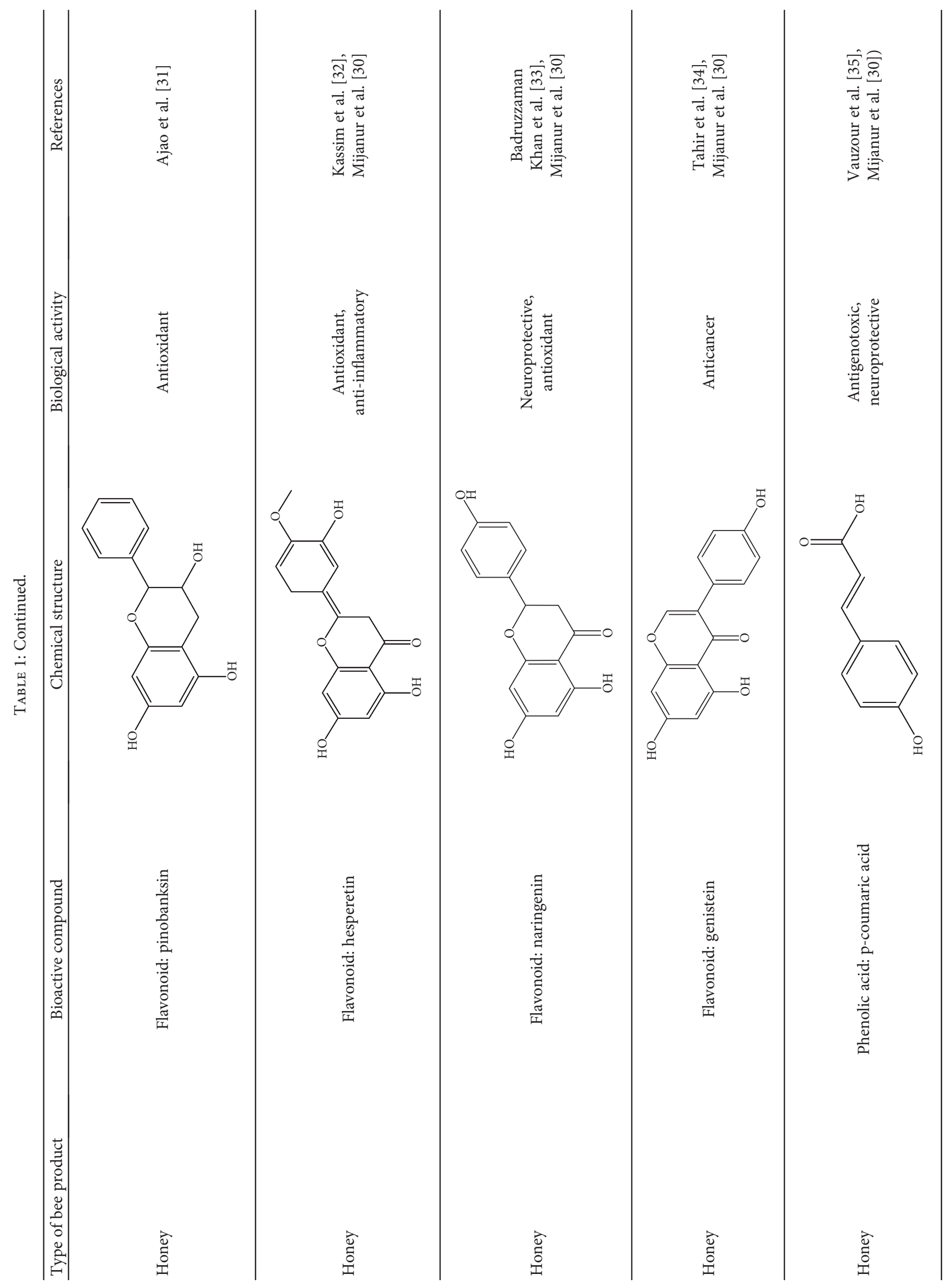




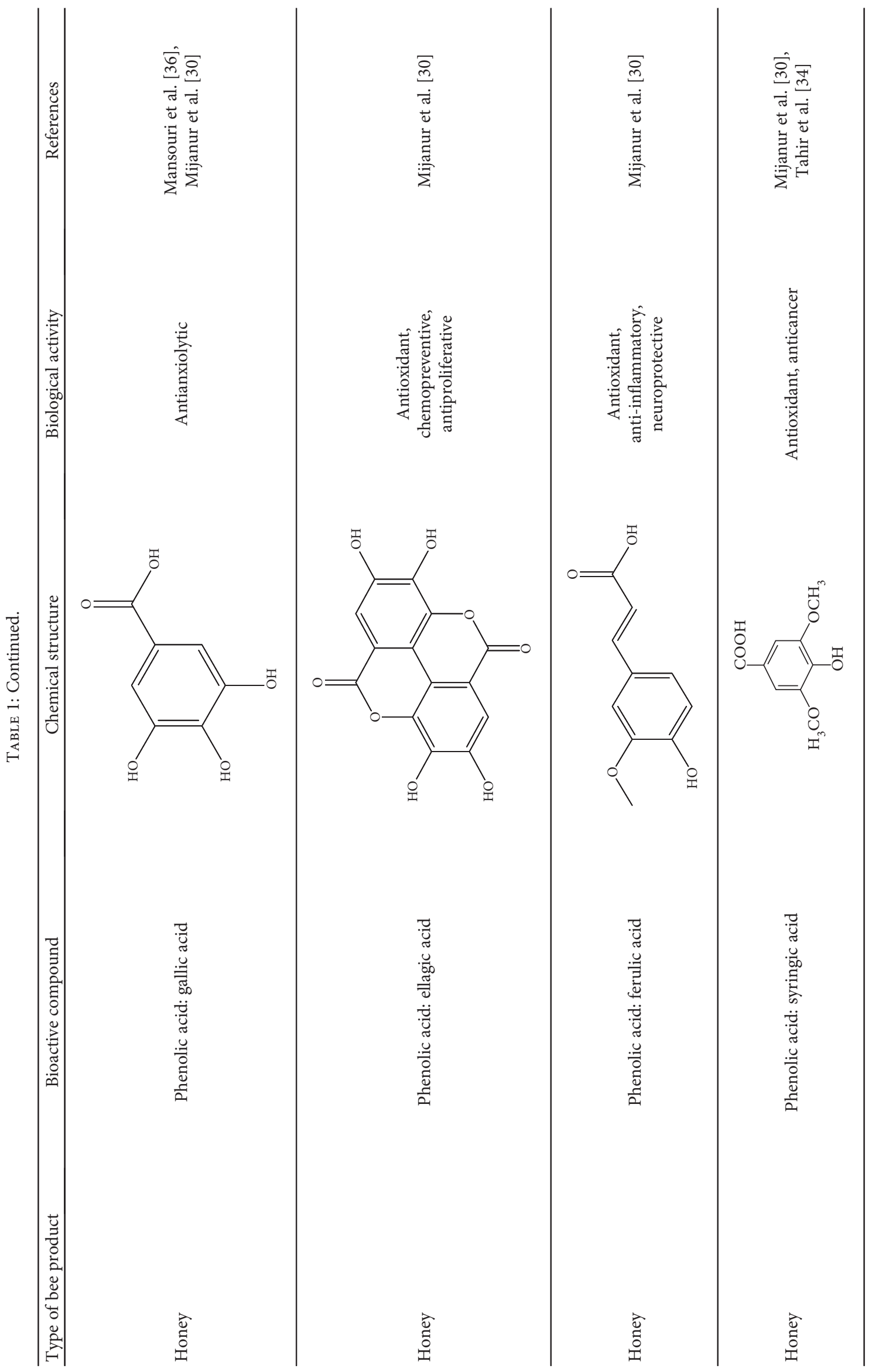




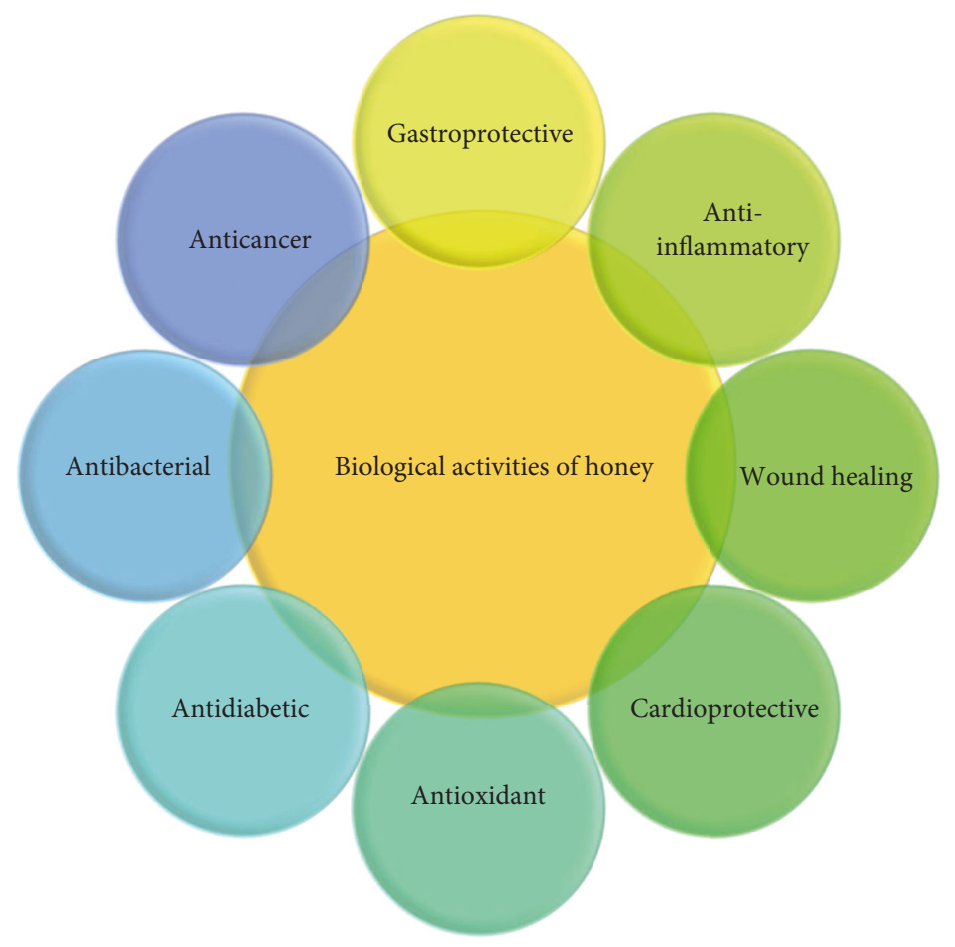

FIgURE 1: Various types of biological activities of honey products.

enzyme. Plasmin causes blood clot retraction and fibrin destructions. It is an enzyme that breaks down fibrin clots with attached dead tissues in the wound bed [38].

Clinical evidence supporting the effectiveness, specificity, and sensitivity of honey in wound care indicates that the performance of conventional and modern wound care dressing is inferior to that using honey [39]. Certain cases have shown that honey stimulates wound-healing properties even in infected wounds that do not respond to antiseptics or antibiotics and wounds that have been infected with antibiotic-resistant bacteria, such as methicillin-resistant Staphylococcus aureus (MRSA) (Natarajan et al. 2001). Honey also aids autolytic debridement and accelerates the growth of healthy granulated wound bed [40].

Malodor is a general attribute of severe wounds caused by anaerobic bacterial species belonging to Bacteroides spp. and Peptostreptococcus spp. [41]. Malodourous compounds, such as ammonia, amines, and sulfur, are produced by bacteria during the metabolism of amino acids from putrefied serum and tissue proteins. These compounds are replaced by lactic acids as honey dispenses a substantial amount of glucose, a substrate metabolized by bacteria in preference to amino acids [42]. The therapeutic effects observed after honey application include fast healing, wound cleansing, clearance of infection, tissue regeneration, minimized inflammation, and increased comfort during dressing due to lower extent of tissue adhesion [43].

4.2. Pediatric Care. Honey also controls skin damage near stomas, such as ileostomy and colostomy, by enhancing epithelialization of the afflicted skin surface [44]. Honey has a beneficial effect on pediatric dermatitis caused by excessive use of napkins and diapers, eczema, and psoriasis. The effect of honey mixed with beeswax and olive oil was investigated on patients with psoriasis or atopic dermatitis condition. A clinical trial showed that a mixture containing honey was extremely well tolerated and caused significant improvements. Honey consists of various nitric oxide metabolites, which reduce the incidence of skin infection in psoriasis [45].

4.3. Diabetic Foot Ulcer (DFU). Consumption of honey is a low-cost and effective therapy for the treatment of DFU. DFU is often complicated by microbial infections and slows the healing process. Apart from the infection, symptoms such as pain, swelling, and redness might not be present for diabetic peripheral neuropathy patients due to their reduced immune response, which further complicates the diagnosis [46]. A review indicated that using honey for the treatment of venous ulcers yielded positive outcomes with good acceptance rates from the patients [47]. Honey is used in wound management and is effective among patients with locally infected wounds, DFU, Charcot foot ulcerations, and complex comorbid conditions that have failed hospital management [48]. In addition, there is excellent tolerability and minimal trauma to the wound bed in the presence of honey.

4.4. Gastrointestinal (GI) Disorder. Natural honey is composed of enzymes that facilitate the absorption of molecules, such as sugars and starch. The sugar molecules in honey are in a form that can be easily absorbed by the body. Honey also provides some nutrients, such as minerals, phytochemicals, and flavonoids, that aid digestive processes in the body [49]. Pure honey has bactericidal properties against pathogenic bacteria and enteropathogens, including Salmonella spp., Escherichia coli, Shigella spp., and many other Gramnegative species [50]. 
The gastrointestinal tract (GIT) contains many important beneficial microbes. For example, Bifidobacteria is one of the microorganisms present primarily for the sustenance of a healthy GI system. It has been suggested that consuming foods rich in probiotics can increase the population of Bifidobacteria in the GIT. The biological activities and development of this bacteria are further enhanced in the presence of prebiotics. Studies have shown that natural honey contains high amount of prebiotics [51]. Some in vitro and in vivo experimental trials on honey have reported it as a prominent dietary supplement that hastens the growth of Lactobacillus and Bifidobacteria and catalyzes their probiotic potency in the GIT $[52,53]$. Under in vitro conditions, prebiotic ingredients in honey such as inulin, oligofructose, and oligosaccharides promoted the increase in the numbers of Lactobacillus acidophilus and L. plantarum by $10-100$ folds, which was beneficial for the intestinal microbiota [54].

4.5. Oral Health. Honey is useful for the treatment of many oral diseases, including periodontal disease, stomatitis, and halitosis. In addition, it has also been applied for the prevention of dental plaque, gingivitis, mouth ulcers, and periodontitis. The antibacterial and anti-inflammatory properties of honey can stimulate the growth of granulation tissue, leading to the repair of damaged cells [55]. Porphyromonas gingivalis is a Gram-negative bacteria that causes periodontitis. Honey exerts antimicrobial activity against this anaerobic bacteria and prevents periodontal disease [56]. Inflammation of mucous membranes in the mouth (stomatitis) may induce redness and swelling of oral tissues and cause distinct and painful ulcers. Honey penetrates into the tissues very quickly and is effective against stomatitis [57, 58]. Halitosis is an oral health condition that causes malodorous breath. Most of the odor in the oral cavity is caused by the activity of degrading microbes [59]. A recent study has reported that honey consumption ameliorates halitosis due to its strong antibacterial activity resulting from its methylglyoxal component [60].

4.6. Pharyngitis and Coughs. Pharyngitis, commonly known as sore throat, is an acute infection induced by Streptococcus spp. in the oropharynx and nasopharynx [61]. In addition to streptococci, viruses, nonstreptococcal bacteria, fungi, and irritants such as chemical pollutants may also cause sore throat. Manuka honey is effective for treating sore throat with its anti-inflammatory, antiviral, and antifungal properties. Honey coats the inner lining of the throat and destroys the harmful microbes while simultaneously soothing the throat $[62,63]$.

A survey has demonstrated that honey is superior to other treatments for cough induced by upper respiratory infections, including dextromethorphan and diphenhydramine [64]. The antioxidant and antimicrobial properties of honey aided in minimizing persistent cough and ameliorated sleep for both children and adults following honey intake $(2.5 \mathrm{ml})$. A comparative study on children with different natural products reported that honey was found to be the widely used remedy for pneumonia $82.4 \%$ [65].
4.7. Gastroesophageal Reflux Disease. Gastroesophageal reflux disease (GERD) is a mucosal infection caused by contents of abnormal gastric reflux into the esophagus and even the lungs. Symptoms of GERD include heartburn, inflammation, and acid regurgitation. Consumption of honey helps this condition by coating the esophagus and stomach lining, thus preventing the upward flow of food and gastric juice. Honey can further stimulate the tissues on the sphincter to assist in their regrowth and finally reduce the chances of acid reflux [66].

4.8. Dyspepsia, Gastritis, and Peptic Ulcer. Dyspepsia is a chronic disease in which the GI organs, mainly the stomach and first part of the small intestine, function abnormally. It is a disease that causes epigastric pain, heartburn, bloating, and nausea as symptoms. Dyspepsia is the preliminary symptom of peptic ulcer which could eventually cause cancer. Gastritis refers to the irritation and inflammation of the lining of the stomach wall. Peptic ulcer denotes erosions or open painful ulcers on the lining of the stomach or duodenum. Honey have been identified as a potent inhibitor for gastritis and the peptic ulcer causing agent, Helicobacter pylori (H. pylori) [67]. Clinical surveys have shown that honey decreased the secretion of gastric acid and increased the healing effect. Thus, honey is taken as a dietary supplement for its antibacterial properties and protective effect [68]. The high sugar content and low $\mathrm{pH}$ in honey are the results of glucose oxidative conversion to gluconic acid by glucose oxidase. This mechanism releases hydrogen peroxide, which functions as an antibacterial agent. Glucose oxidase also acts on fibroblasts and epithelial cell activators required for the healing of ulcers caused by $H$. pylori [51].

4.9. Gastroenteritis. Gastroenteritis, known as stomach or gastric flu, causes inflammation of the digestive tract. This condition may be due to foodborne, waterborne, and person-to-person spread of infectious agents. The symptoms of gastroenteritis include dehydration, watery diarrhea, bloating, abdominal cramps, and nausea. There are many infectious agents, such as Salmonella, Shigella, and Clostridium, that can cause this condition [69]. A clinical study by Abdulrahman, 2010, has reported the treatment of infantile gastroenteritis using honey. The study found that replacing the glucose in standard electrolyte oral rehydration solution (ORS) with honey reduced the recovery time of patients with gastroenteritis because the high sugar content in honey boosts electrolyte and water reabsorption in the gut [70].

4.10. Constipation and Diarrhea. Chronic constipation is a common and multifarious illness characterized by intolerable defecation (irregular stools and difficult stool passage). Difficult stool passage includes symptoms such as straining, hard to expel stool, a sense of incomplete evacuation, hard or lumpy stools, and prolonged time to pass stool [71]. Diarrhea is defined as a high frequency of bowel movements with watery stool. Honey has minimized the pathogenesis and duration of viral diarrhea compared to conventional antiviral therapy [72]. In another case, people diagnosed with inflammatory bowel syndrome (IBS) experiencing severe 
diarrhea or constipation, bloating, and stomach discomfort was successfully treated with raw Manuka honey on an empty stomach [73].

4.11. Liver and Pancreatic Diseases. Honey helps to soothe pain, balance liver systems, and neutralize toxins. Complications in the liver system can be attributed to oxidative damage. Honey exhibits antioxidant activities that have a potential protective effect on the damaged liver. A study on paracetamol-induced liver damage rats showed that the antioxidant and hepatoprotective activity of honey minimized liver damage [74]. Honey, which has a 1:1 ratio of fructose to glucose, may help to promote better blood sugar level, which is useful for those suffering from fatty liver disease since it provides adequate glycogen storage in liver cells. Insufficient glycogen storage in the liver releases stress hormones that impair glucose metabolism over time. Impaired glucose metabolism leads to insulin resistance and is the main factor of fatty liver disease. Another study reported significant reduction in blood glucose levels after treatment with Tualang honey $[75,76]$.

4.12. Metabolic and Cardiovascular Health. Natural wild honey exerts cardioprotective and therapeutic impacts against epinephrine-induced cardiac disorders and vasomotor dysfunctions. A harmonized relationship between radical scavenging activity and the total phenolic content of honey has been observed [77]. Honey intake showed a significant reduction in risk factors of metabolic and cardiovascular diseases. Honey exhibits cardioprotective effects such as vasodilation, balancing vascular homeostasis, and improvements in lipid profile [78]. Flavonoids in honey improves coronary vasodilation, decreases the ability of platelets to form clots, prevents oxidation of low-density lipoproteins (LDL), increases high-density lipoproteins (HDL), and improves endothelial functions [79].

A study conducted to compare the metabolic response of honey has indicated its ameliorative effects against metabolic syndromes (MetS) [80]. MetS is denoted by hyperglycemia, hypertension, abdominal obesity, dyslipidemia, and intensified adaptability towards diabetes, kidney, and heart diseases. Polyphenols in honey reduce atherosclerotic lesions through the downregulation of inflammatory and angiogenic mechanisms [81]. A clinical study conducted on patients with hyperlipidemia showed that honey decreased total cholesterol (TC) and noticeably prevented the rise in plasma glucose levels. Nitric oxide (NO) is a metabolite present in honey that also has cardioprotective functions [82].

\subsection{Cancer and Oncogenesis}

4.13.1. Breast Cancer. Imbalance in estrogen signaling pathways and propagating levels of estrogens have important roles in breast cancer growth and propagation [83]. Treatments for breast cancer are associated with targeting the estrogen receptor (ER) signaling pathway. Phytoestrogens are a subclass of phytochemicals with a common structure to the mammalian estrogen that enables them to bind to estrogen receptors. Several experimental studies have investigated the efficiency of honey in modulating the ER signaling pathway [84]. Another study has shown that honey has biphasic activity in MCF-7 cells. This biphasic activity of honey is represented by an antiestrogenic effect at lower concentrations and an estrogenic effect at higher concentrations, which is caused when phytoestrogens bind to estrogen receptors [85]. Moreover, quercetin has been reported to induce apoptotic effects through ER $\alpha$ - and ER $\beta$-dependent mechanisms. On the other hand, cytotoxic activities of Tualang honey in human breast cancer cells were demonstrated by elevated secretion of lactate dehydrogenase (LDH) and further illustrated the cytotoxic properties of honey. The study also showed that honey only exerts cytotoxic effects on breast cancer line and not on nonmalignant breast cells. Therefore, this indicates that Tualang honey shows highly specific and selective cytotoxic effects towards breast cancer cell lines and has a good potential as a chemotherapeutic agent [86].

4.13.2. Liver Cancer. The most common type of liver cancer is hepatocellular carcinoma (HCC). The antitumor effects of honey on liver cancer cells have been investigated in various experimental studies. Treatment of HepG2 cells with honey minimized the amount of nitric oxide (NO) levels in the cells and decreased the HepG2 cell number greatly. This increased the overall antioxidant profile of the cells. The survival of HepG2 cells is promoted by reactive oxygen species (ROS), and adequate levels of ROS trigger cell proliferation and differentiation. Decreasing the amount of NO resulting from honey treatment supported this study. Thus, reduced ROS and enhanced antioxidant efficacy inhibit cancerous cell proliferation and lowered the number of HepG2 cells [84]. Another study done by Abdel Aziz et al. investigated the effects of honey on HepG2 cell lines. The report showed that honey exerted cytotoxic, antimetastatic, and antiangiogenic effects on HepG2 cells based on different concentrations [87].

4.13.3. Colorectal Cancer. Most colorectal cancers begin as a polyp, which generally starts on the inner lining of the colon or rectum and grows towards the center. Some polyps are not dangerous but some will eventually grow into adenomas and can eventually result in cancer. A study [88] that investigated the chemopreventive effects of Gelam and Nenas monofloral honeys against colon cancer cell lines found that the honey inhibited proliferation of colon cancer cells. Hydrogen peroxide-induced inflammation in the colon cancer cells was used to examine the effect of honey. The results showed that honey curbed inflammation in the cancerous cells [88]. Another study was done to investigate the apoptotic effects of crude honey on colon cancer cell lines. The study confirmed the antiproliferative effect of honey in these cells. In addition, at high phenolic concentrations (such as those of quercetin and flavonoids), significant antiproliferative action against colon cancer cells was observed [89].

The molecular mechanisms resulting in the antiproliferative and anticancer effects of honey include cell cycle arrest, activation of mitochondrial pathway, induction of mitochondrial outer membrane permeabilization, induction of apoptosis, modulation of oxidative stress, reduction of inflammation, modulation of insulin signaling, and inhibition of angiogenesis in cancer cells (Figure 2). In addition, 


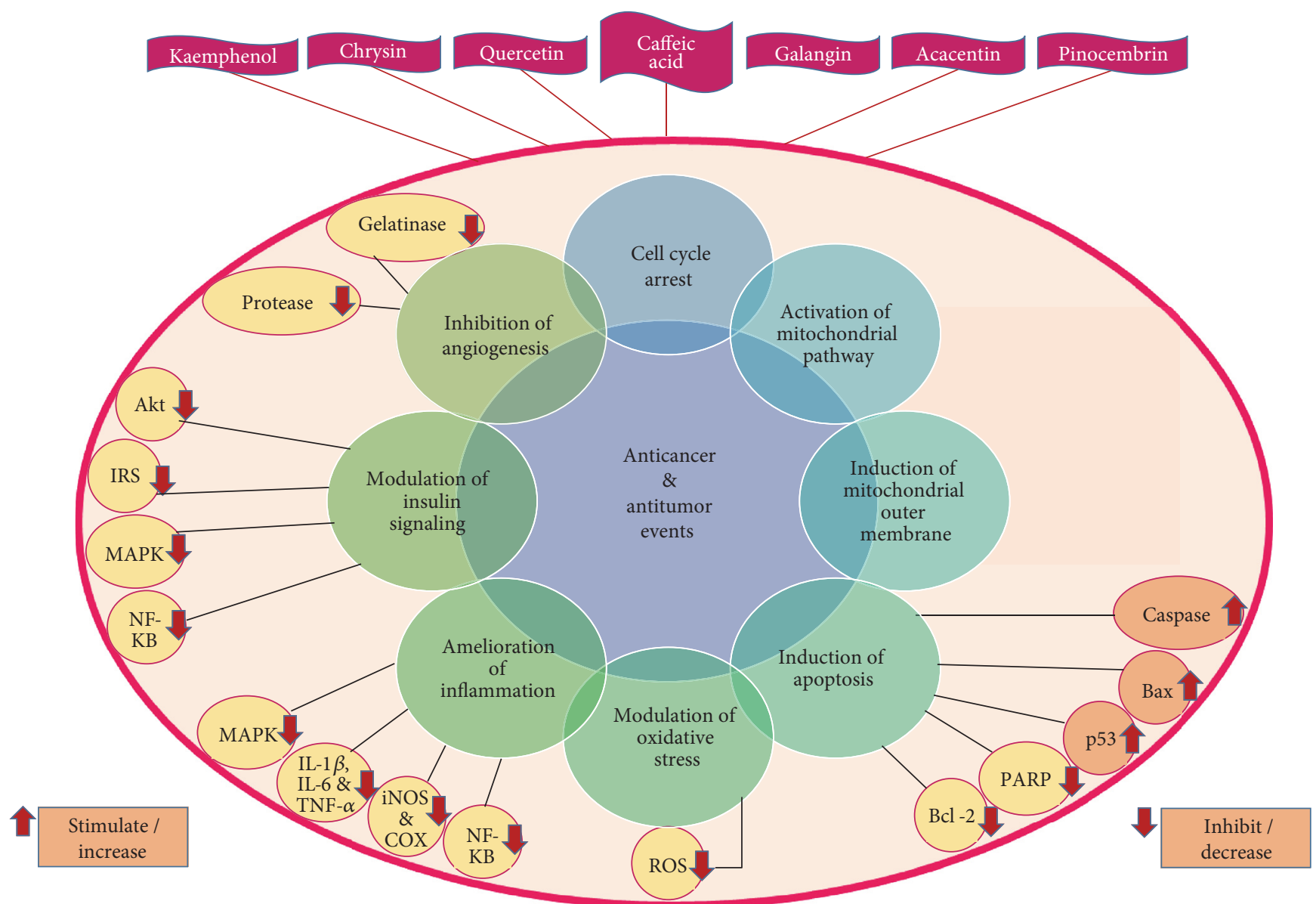

FIGURE 2: Molecular mechanisms responsible for anticancer and antitumor activities of honey products. IRS-insulin receptor substrate, MAPK-mitogen-activated protein kinase, NF- $\kappa$ B-nuclear factor kappa B, IL- $\beta$-interleukin-1 beta, IL-6-interleukin-6, TNF$\alpha$-tumor necrosis factor alpha, iNOS-inducible nitric oxide synthase, COX_cyclooxygenase, ROS-reactive oxygen species, Bcl-2-Bcell lymphoma-2, and PARP—poly (ADP-ribose) polymerases.

honey shows potential effects on cancer cell by modulating proteins, genes, and cytokines that promote cancer.

Several components of honey such as chrysin, quercetin, and kaempferol have been shown to arrest cell cycle at various phases such as G0/G1, G1, and G2/M in human melanoma, renal, cervical, hepatoma, colon, and esophageal adenocarcinoma cell lines. The mitochondrial pathway entails a chain of interactions between stimuli such as nutrients, physical stress, oxidative stress, and damage during major cancer treatments including chemotherapy and radiotherapy. These stimuli cause several proteins located within the intermembrane space (IMS) of the mitochondria, such as cytochrome c, to be released, which eventually culminates in the death of the cell. Flavonoids in honey are effective in activating the mitochondrial pathway and discharging proteins with potential cytotoxicity. Induction of mitochondrial outer membrane permeabilization (MOMP) is the most prevalent anticancer mechanism, which causes the leakage of proteins from the IMS and inevitably results in cell death. Honey induces MOMP in cancer cell lines by decreasing the mitochondrial membrane potential. Honey has also been documented for amplifying the apoptotic effect of tamoxifen by intensified depolarization of the mitochondrial membrane. Flavonoid constituents of honey, such as quercetin, have been shown to trigger MOMP and lead to cancer cell death [84].

Apoptosis is a programmed cell death functioning to control cell growth and remove damaged cells from the system. This process also involves MOMP and results in the discharge of IMS proapoptotic proteins such as cytochrome $\mathrm{c}$ to activate caspase cascades which results in further disruption of mitochondria and finally results in cancer cell death. Influence of honey on enzymes, genes, and transcription factors corresponding to apoptosis has been investigated. Poly (ADP-ribose) polymerases (PARP) are crucial enzymes involved in apoptosis and DNA repair. Inhibition of PARP activity renders the cells unable to repair damaged DNA and pass through the G2 and M phases of the cell cycle. Thus, cell cycle is arrested. Because DNA repair is impaired due to nonfunctioning PARP, the cells are being classified as damaged, and consequently, apoptosis activity may be augmented.

Inhibition of PARP activity by flavonoids in honey is a potential strategy for targeting cancers with defective DNAdamage repair. Bcl-2 and Bax are antiapoptotic and proapoptotic proteins, respectively. $\mathrm{Bcl}-2$ is generally overexpressed 
in cancer. Tumor suppressor p53 is a transcription factor commonly inactivated in various types of tumors. It modulates transcription of genes involved in apoptosis [84, 90]. Honey enhances the upregulation of Bax and downregulation of Bcl-2. In addition, it activates caspases 3 and 9 and induces p53, thereby inhibiting cancer.

Low levels of ROS intensify cell proliferation while high levels lead to oxidative damage that contributes to various types of cancer. Regulation of redox homeostasis is vital for normal cell growth and proliferation. In this regard, honey is an influential antioxidant and free radical scavenger. The inhibitory effect of honey on cancer growth and proliferation is due to its ability to modulate oxidative stress. Honey exhibits anticancer properties via antioxidant or prooxidant mechanisms that are selectively dependent on the state of oxidative stress in the cancer cells. If cancer growth is rapid under high levels of ROS, honey acts as an antioxidant to prevent cancer cell growth by minimizing oxidative stress and scavenging the ROS. On the other hand, under low levels of ROS, it may also act as a pro-oxidant and promotes cancer cell growth by further generation of ROS and maximizing oxidative stress. Thus, the effects of honey on cancer cell death are different under different conditions [84].

Inflammation is a contributing factor for the dysregulation of physiological processes, which leads to various malignancies and cancers. Mitogen-activated protein kinase $(\mathrm{MAPK})$ and nuclear factor kappa $\mathrm{B}(\mathrm{NF}-\kappa \mathrm{B})$ are the two main pathways responsible for inflammatory response in cells. Activation of MAPK and NF- $\kappa \mathrm{B}$ activates proinflammatory genes and generates inflammatory proteins or cytokines. These include cyclooxygenase-2 (COX-2), Creactive protein (CRP), lipoxygenase-2 (LOX-2), interleukins (IL-1 $\beta$, IL-6), and TNF- $\alpha$. These components play crucial roles in both angiogenesis and inflammatory responses corresponding to cancer. IL- $1 \beta$, IL- 6 , and TNF- $\alpha$ are cytokines that trigger cancer cell proliferation by maintaining the inflammatory phenotype in the tumor microenvironment. On the other hand, cyclooxygenase-2 (COX-2) and inducible nitric oxide synthase (iNOS) yield essential endogenous factors responsible for the tumor progression. The actions of iNOS can be either inductive or inhibitory depending on the tumor types.

Biological responses which facilitate inflammation can promote tumorigenesis as severe inflammation is the major factor for the development of cancer cells. Treating and soothing of inflammation aid to suppress the configuration of malignant and benign tumors. Honey helps to reduce the promotion and tumorigenesis and progression of cancer by reducing the expression of MAPK and NF- $\kappa \mathrm{B}$ in cancerous cells. MAPK cascades are the main signaling pathways in the regulation of cell proliferation, survival, and differentiation. $\mathrm{NF}-\kappa \mathrm{B}$ is a transcription factor which is vital in the regulation of immune responses, inflammation, and oncogenesis. NF- $\kappa \mathrm{B}$ translocation to the nucleus and reduced $\mathrm{I} \kappa \mathrm{B} \alpha$ degradation help to regulate the expression of genes involved in apoptosis and proliferation that are responsible for the development of cancer. Flavonoids found in honey have been shown to induce apoptosis and prevent the release of IL- $1 \beta$, IL-6, TNF- $\alpha$, iNOS, and COX-2 [84].
Tumors, malignancies, and cancers are usually enhanced by obesity and insulin-resistant type 2 diabetes mellitus. PI3K/Akt is an important pathway in insulin signaling. The PI3K/Akt pathway is also recognized in modulating substrates that are related to cellular growth, survival, and progression. Elevated levels of $\mathrm{MAPK}, \mathrm{NF}-\kappa \mathrm{B}$, and insulin receptor substrate 1 (IRS-1) along with reduced levels of Akt expression have been actively linked to the development of insulin resistance. Honey components such as quercetin revive insulin resistance by increasing the expression of Akt while reducing the expression of IRS, MAPK, and NF- $\kappa \mathrm{B}$. Modulation of insulin signaling by honey leads to anticancer activities [84].

Honey has debridement effects by boosting epithelialization and stimulates the development of granulation tissue through its angiogenic effect on the vasculature. Honey selectively stimulates angiogenesis in noncancer tissues through the production of hydrogen peroxide while inhibiting angiogenesis in cancer tissues. Honey has antiangiogenic effects that prevents the wound-healing response, reduces the viability of cancer cells, and lowers the incidence of metastasis by inhibiting the activities of gelatinase and protease. Honey prevents the development of cancer by blocking the three main stages of cancer formation known as initiation, proliferation, and progression [84].

\section{Health Benefits of Propolis}

5.1. Gastrointestinal Disorder. Infection with parasites usually occurs upon contact with an infected surface. The symptoms of parasitic infection of the GI tract include abdominal pain, diarrhea, bloating, and nausea. Propolis has been reported to have several biological efficacies including anticancer, antioxidant, and anti-inflammatory activities (Figure 3). There are a few studies that reported the clinical use of propolis in the treatment of viral infections. In one study, the in vitro effect of propolis ethanolic extract on the growth and adherence of Giardia duodenalis trophozoites was evaluated [91]. Propolis was shown to inhibit growth and adherence of the trophozoites. It also promoted the detachment of these parasitic organisms. Its efficacy against giardiasis has also been reported in a clinical study whereby children and adults with giardiasis-given propolis showed a cure rate between $52 \%$ and $60 \%$, whereas those given the conventional drug showed a $40 \%$ cure rate. Another experimental study showed that propolis has antihistaminergic, antiinflammatory, antiacid, and anti-H. pylori activities that can be used to treat gastric ulceration [92].

5.2. Gynecological Care. Widespread causes of indicative vaginitis are bacterial vaginosis (BV) and vulvovaginal candidiasis (VVC). The depletion of Lactobacillus spp. in the vagina is a distinguished feature of vaginal infections. The infection is accompanied by an overgrowth of vaginal pathogens such as yeast-like fungi and an elevated vaginal $\mathrm{pH}$. Diabetes patients are more prone to having vaginal infections caused by Candida albicans. A study conducted on the application of $5 \%$ aqueous propolis solution resulted in an improvement in vaginal well-being [93]. In addition 


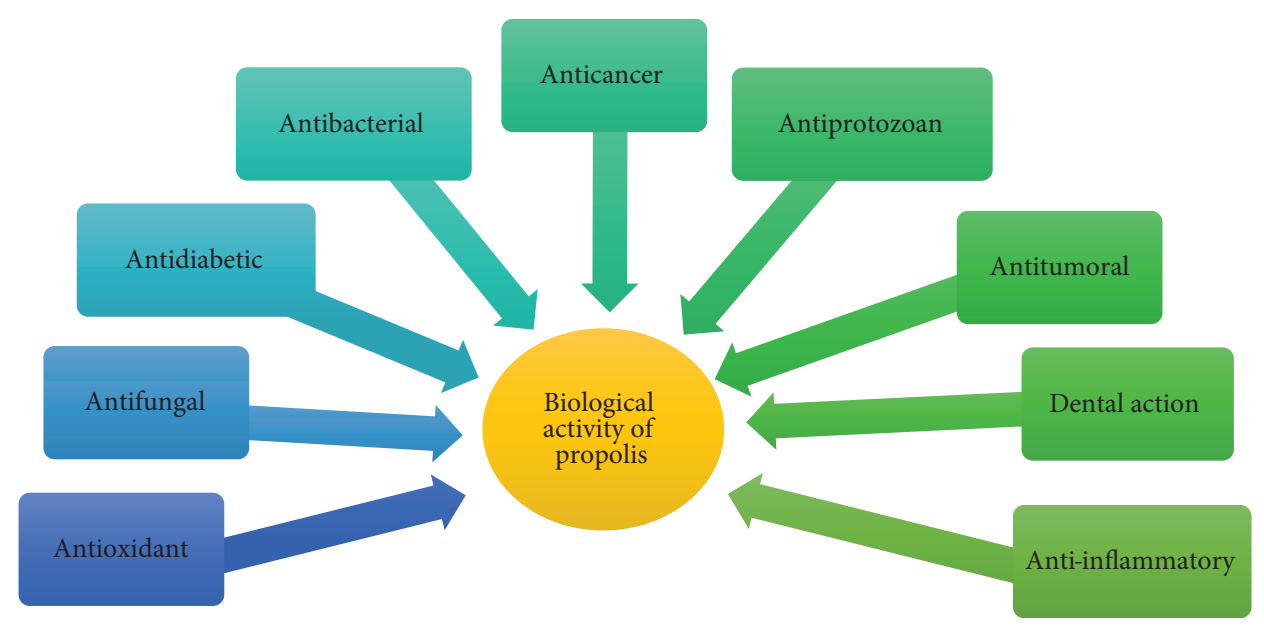

FIgURE 3: The biological activities of propolis.

to providing antibiotic and antimycotic actions, propolis provides early symptomatic relief due to its anesthetic properties. Thus, propolis may be used for Recurrent Vulvovaginal Candidiasis (RVVC) and can be an alternative option for patients who are unable to take antibiotics due to a concurrent pharmacological treatment. The effectiveness of propolis against conventional antifungal nystatin has shown satisfactory results. Propolis extract solution (PES) also show low toxicity in human cells and can be an alternative treatment for chronic vaginitis. In addition, PES has antifungal properties and it can be used as antibiofilm material for RVVC to counteract biofilm growth of C. albicans and resistance in antifungal drug [94].

5.3. Oral Health. The oral cavity has an abundant bacterial microflora and excessive bacterial growth may lead to several conditions such as oral diseases. Studies have shown that propolis may restrict bacterial-plaque development and periodontitis-causing pathogens because of its antibacterial properties [95]. Propolis solutions exert a selectively lower cytotoxic action on human gum fibroblasts compared to chlorhexidine. In addition to that, mouthwash containing propolis have shown effectiveness in healing surgical wounds. This encourages the use of propolis in solutions used as mouthwash [96]. Propolis solution can also be used to disinfect toothbrushes [97]. A 3\% ethanolic extract of propolis toothpaste gel showed greater potency against gingivitis caused by dental plague in a group of patients [98]. Propolis extracts have also helped cure halitosis, a condition where an individual experiences unpleasant breath predominantly due to poor oral hygiene. Propolis toothpaste or mouthwash is used for their ability to reduce growth of bacterial plaque and pathogenic microflora that causes gingivitis and periodontitis. Thus, propolis also plays a role as a therapeutic agent [95].

5.4. Oncological Treatment. A study reported that propolis has potential towards human breast cancer treatment due to its antitumor activity by inducing apoptosis on human breast cancer cells. It also exhibits low or no toxicity towards normal cells due to its selectively toxic properties against tumor cells and is believed that propolis may become a prominent agent to treat breast cancer [99]. Another study investigating the effect of ethanolic extract of Algerian propolis on melanoma tumor growth has shown that galangin, a common flavonoid in propolis remarkably induced apoptosis and inhibited melanoma cells in vitro [100]. Turkish propolis has also been shown to exert a selective cytotoxic action on human lung cancer cells by inducing endoplasmic reticulum stress, apoptosis, and caspase activity and by reducing the mitochondrial membrane potential. This indicates that propolis is able to minimize the cancer cell proliferation [101].

5.5. Dermatological Care. Propolis is widely used in dermatological products such as creams and ointments. Its use in skin care products is based on its antiallergy, antiinflammation, antimicrobial properties, and promotive action on collagen synthesis. A recent study comparing the effect of propolis and the conventional drug silver sulfadiazine showed that propolis notably decreased free radical activity in healing the wound beds which supported the repair process. A clinical study on acne patients using ethanolic extract propolis showed its high efficacy in the treatment of acne vulgaris [102]. Propolis also shows positive collagen metabolism in the wound during the healing process by increasing the collagen content of tissues [103]. A study demonstrated the use of propolis as an alternative therapy for wound healing to promote wound closure, especially under conditions such as human diabetic foot ulcer (DFU) [104].

The molecular mechanisms responsible for the woundhealing activity of propolis is shown in Figure 4. Fibronectin (FN) is a multifunctional glycoprotein of high molecular weight, which influences the structural stability and functional properties of various organs and tissues (Stoffels, 2013). The fibronectin matrix and its accumulation are essential for cell migration, cell proliferation, cell differentiation, cell adhesion, apoptosis, cellular signaling, angiogenesis, collagen biosynthesis, re-epithelialization, clot formation, 


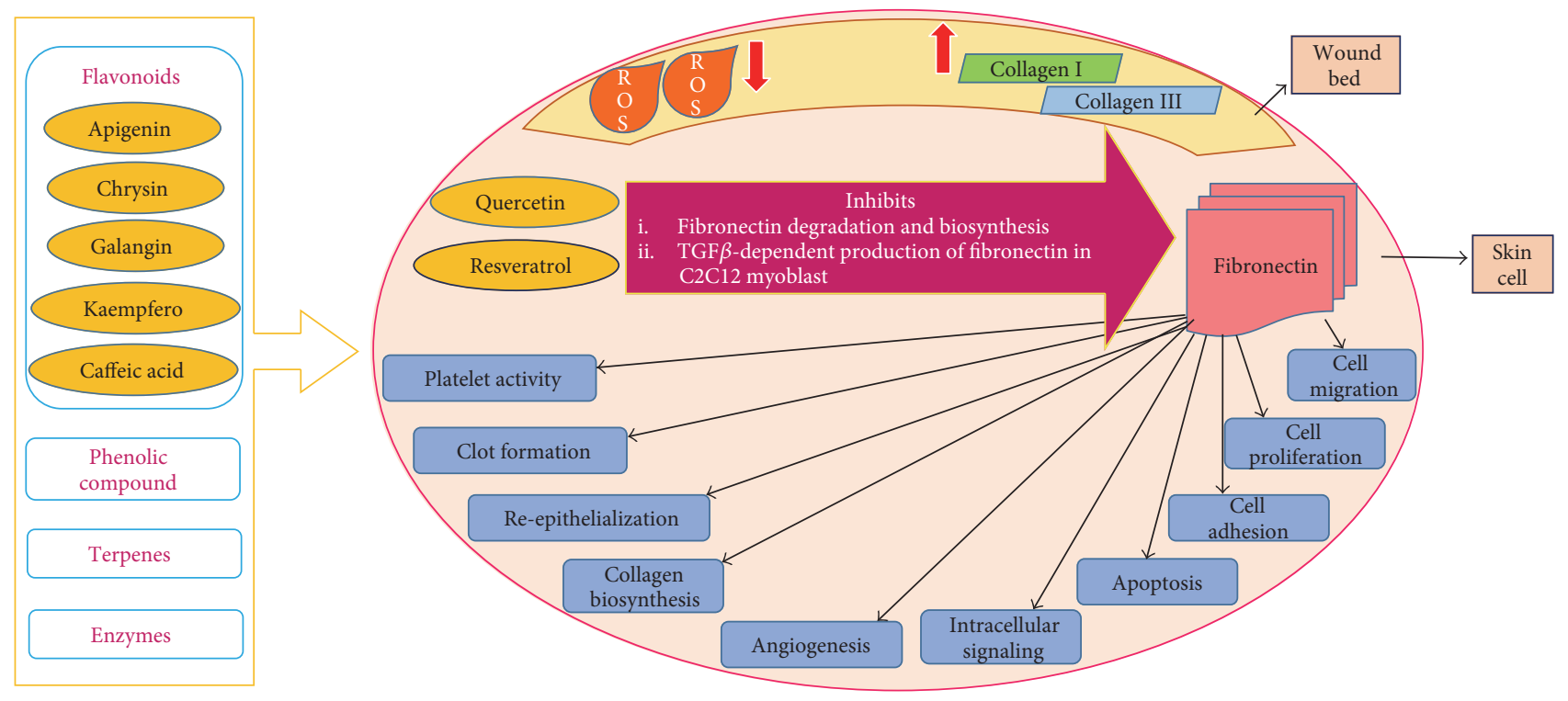

FIGURE 4: Molecular mechanism targeting wound-healing activity of propolis.

and platelet activity. Fibronectins are also important in the repair mechanisms for conditions such as glycoprotein intensified degradation, which leads to a defective cellular microenvironment and affliction in the structure of granulation tissues. This condition may prevent the wound from healing or inhibit the repair process. The accumulation of fibronectin in the extracellular space also modulates the secretion of other repairing components such as collagen type I and type III, tenascin, laminin, and fibrillin.

Propolis has demonstrated favorable effects in the wound-healing process such as antifungal and antibacterial activities due to its components such as flavonoids, phenolic compounds, terpenes, and enzymes. It also reduces the activity of free radicals (ROS) in the wound bed favoring the repair process. Propolis has also demonstrated great effects on collagen metabolism by increasing the amount of both type I and type III collagens in tissues. The reduction of ROS and accumulation of collagen aid in balancing the extracellular matrix and generating granulation tissues. Propolis is a potential apitherapeutic agent that is able to modify the metabolism of fibronectin by developing a fibrous network of extracellular matrix and inhibiting fibronectin disintegration. The active components in propolis such as quercetin and resveratrol inhibited fibronectin biosynthesis and TGF?-dependent production of fibronectin, respectively, in $\mathrm{C} 2 \mathrm{C} 12$ myoblasts. Both the components play important roles in regulating the expression of fibronectins. Studies have also shown that mobility and migration of epithelial cells are dependent on reduced fibronectin content in the extracellular matrix. Reduced amounts of this glycoprotein in propolis effectively treated wounds and produced granulation tissues. Therefore, the influence of propolis on fibronectin metabolism may alter the mechanism of wound healing [103]. Several health benefits of propolis related to gastrointestinal, gynecological care, oral health, skin care, and oncological treatments are tabulated in Table 2 .

\section{Health Benefits of Royal Jelly}

Royal jelly is one of the honey bee products which have potential towards various human disease treatments. Figure 5 depicts the biological activities of royal jelly as an antioxidant, antitumor, antiaging, neurotropic, and antiinflammatory agent.

6.1. Reproductive Health. A randomized clinical study has reported that royal jelly is effective in reducing premenstrual syndrome [105]. A randomized clinical trial study reported the effectiveness of royal jelly in treatment of urinary problems and promotion of life quality in postmenopausal women [106]. Royal jelly has protective effects against Oxymetholone-induced reproductive toxin (OXM), which is an active steroid derived from testosterone as a defense mechanism. Recent studies have reported that royal jelly protects against the oxidative injuries in the mouse testes and that it contains spermatogenesis-stimulating compounds, which inhibit the production of proinflammatory cytokines [107]. Another study on male rabbits has indicated its positive effects on fertility, semen quality and output, and concentration of testosterone, total proteins, and glucose in the blood. The number of dead and abnormal sperm decreased with the reduction of biomarkers of oxidative stress [108]. Royal jelly has been traditionally used to treat menopause symptoms by rebalancing the hormonal concentration in the blood, decreasing follicle-stimulating hormones (FSH) and increasing the estrogen concentration in aged mice. A study showed that the changes in hormone levels resulting from royal jelly increased the amount of ovulated oocytes and their quality in aged rats [109].

The molecular mechanisms responsible for the antiaging activity of royal jelly are shown in Figure 6. The quality of oocytes decreases with age and the depleted follicle pool hastens hormonal dysregulation. This hormonal dysfunction is responsible for the reduction in ovarian follicle size and 
TABLE 2: Selected propolis activities according to the health benefits.

\begin{tabular}{lccc}
\hline Health benefits & Propolis activity & Type of studies & Authors \\
\hline \multirow{2}{*}{ GI disorder } & Antiparasitic & Humans & Freitas et al. 2006 [91] \\
& Antiulceration & Animals & Paulino et al. 2015 [92] \\
\hline \multirow{2}{*}{ Gynecological care } & Antifungal & Human & Imhof et al. 2005 [93] \\
& Antifungal and antibiofilm & Human & Capoci et al. 2015 [94] \\
\hline & Antibacterial & Pereira et al. 2011 [95] \\
Oral health & Daily mouthwash & Hain et al. 2014 [96] \\
& Toothpaste disinfection & Haboratory & Bertolini et al. 2012 [97] \\
& Toothpaste against gingivitis & Skaba et al. 2013 [98] & Pereira et al. 2011 [95] \\
\hline & Oral therapeutic agent & Human & Xuan et al. 2014 [99] \\
Oncology treatment & Anti-breast cancer & Human & Benguedouar et al. 2015 [100] \\
& Antimelanoma cancer & Human & Demir et al. 2016 [101] \\
\hline & Anti-lung cancer & Animals & Ali et al. 2015 [102] \\
Dermatology care & Acne vulgaris & Human & Olczyk et al. 2014 [103] \\
& Collagen metabolism & Human & Henshaw et al. 2014 [104] \\
\hline
\end{tabular}

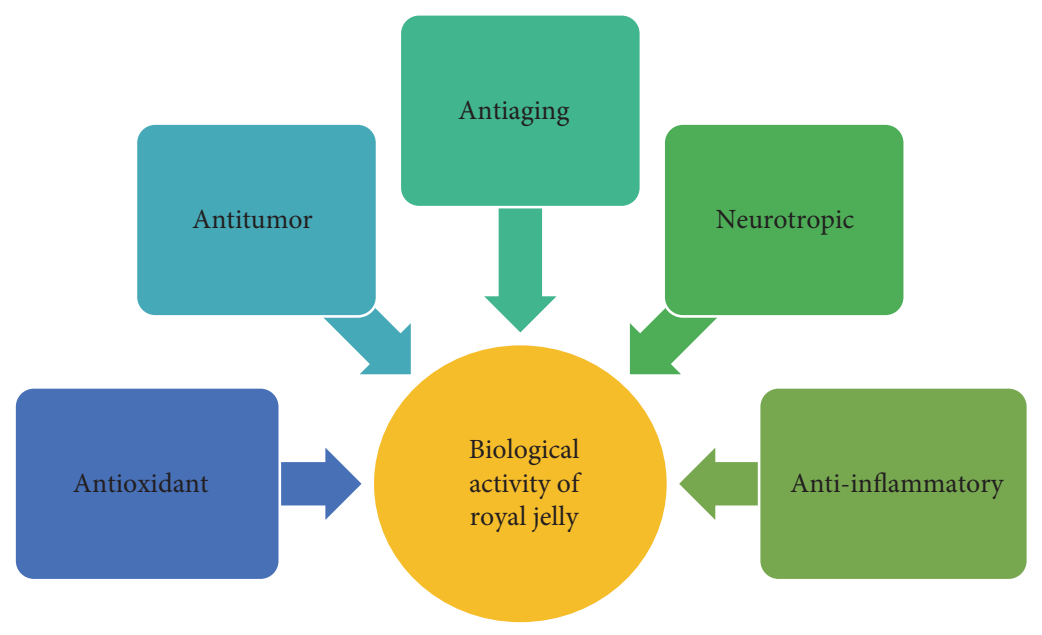

Figure 5: Different types of biological activities of royal Jelly.

oocyte quality. Oxidative stress is the main cause of aging. Increased oxidative stress and continuous ovulation causes loss of antioxidants such as SOD, catalase, and glutathione S-transferase (GST). It also minimizes the size of the follicle pool and oocyte quality. Oxidative stress is controlled by glutathione (GSH), glutathione S-transferase (GST), Glutathione S-Transferase Theta 1 (GSTT1), Bax, and Bcl-2. GSH, GST, and GSTT1 are direct ROS scavengers, which play a vital role in removing oxidative stress from the cell. Higher expression of Bax and lower expression of $\mathrm{Bcl}-2$ also promote aging and reduces oocyte quality.

FSH and luteinizing hormone (LH) are the hormones involved in the aging process. The amount of FSH and $\mathrm{LH}$ is controlled by estrogen (E2) and inhibin from the ovarian cells. Reduction of the follicle pool size results in an inadequate release of estrogen and inhibin, which results in a rise in FSH levels. This process then aids in the reduction of the follicle pool size and affects oocyte quality. This process promotes aging in the ovaries. In young ovarian cells, higher amount of estrogen (E2) and inhibins are needed to decrease the level of FSH and LH. This adaptation can be overcome by antiaging therapies such as supplemental consumption of royal jelly. The major active component present in royal jelly is 10-hydroxyl-2-decenoic acid. This compound enhances the synthesis of ovulation hormones, maintaining a lower expression of FSH and LH in young ovarian cells. It is also efficient in preventing the depletion of follicle pool and in enhancing hormonal regulation. Thus, royal jelly helps in preventing the aging process and is an influential antiaging product [109].

6.2. Neurodegenerative and Aging Diseases. Poor mental state and performance such as in the case of Alzheimer's disease (AD) are mostly experienced by elderly individuals due to aging. Royal jelly stimulates physical and mental functions for the elderly and increases their appetite and weight. A 


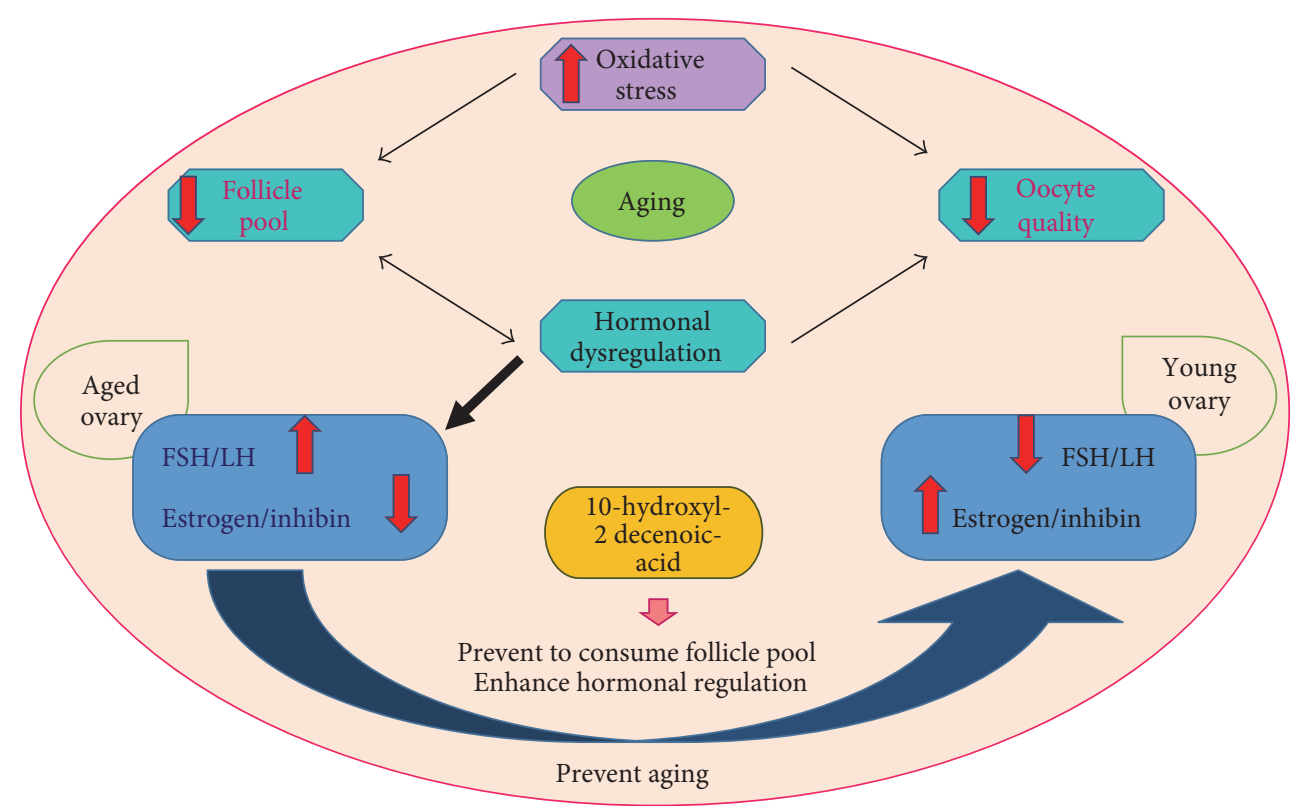

Figure 6: Molecular mechanism responsible for the antiaging activity of royal jelly.

TABLE 3: Reports on health benefits of royal jelly.

\begin{tabular}{lccc}
\hline Health benefits & Propolis activity & Type of studies & Authors \\
\hline & Antioxidant & Animals & El-Hanoun 2012 [108] \\
Reproductive care & Hormone balance & Animals & Imai et al. 2012 [109] \\
& Antioxidative agent & Animals & Najafi et al. 2014 [107] \\
& Reduce premenstrual syndrome & Humans & Taavoni et al. 2014 [105] \\
& Postmenopausal treatment & Humans & Seyyedi et al. 2016 [106] \\
\hline & Longevity promoting & Animals & Honda et al. 2011 [111] \\
Neurodegenerative and aging disease & Alzheimer's disease & Animals & Zamani et al. 2012 [110] \\
& Mental health & Human & Morita et al. 2012 [112] \\
\hline & Fibroblast migration & Animals & Kim et al. 2010 [113] \\
Wound healing & Collagen production & Human & Park et al. 2011 [114] \\
& Vasodilatation & Human & Siavash et al. 2015 [115] \\
\hline
\end{tabular}

study showed that royal jelly exerted neuroprotective effects in $\mathrm{AD}$ [110]. The behavioral and neurochemical effect of royal jelly was chemically examined in aged rats. The study confirmed a better cognitive performance and increased the life span in the older animals that had been given royal jelly. Another study reported that royal jelly contains longevitypromoting factors and extends the lifespan in the nematode Caenorhabditis elegans [111]. Another study have also reported the improved mental health in human upon ingestion of royal jelly for six months [112]. A few studies on the health benefits of royal jelly are given in Table 3 .

6.3. Wound Healing. Royal jelly enhances wound-healing activity. In both in vivo and in vitro wound-healing models, under the effect of royal jelly, human fibroblasts were able to migrate and increase levels of sphingolipids by decreasing the secretion and formation of collagen. Thus, royal jelly shortened the curing period of desquamated skin lesions
[113]. Another study on the use of royal jelly have also exhibited protective action on human skin against ultraviolet Binduced photoaging by promoting collagen production [114]. Royal jelly dressing is also an effective way of treating diabetic foot ulcers besides standard treatments. This is due to its vasodilation effects around the affected wound, which can help to dilate the blood vessels to enhance blood flow. It also helps to prevents infections due to its antimicrobial activities [115].

\section{Conclusion and Future Prospects}

The present review focused on the potential health benefits of bee products such as honey, propolis, and royal jelly. These products are highly rich in active components such as flavonoids, phenolic acid, phenolic compounds, terpenes, and enzymes, which have biological functions in preventing some diseases and promoting good health. Honey, propolis, and 
royal jelly have distinct efficacies with significant nutritional properties and functional values. Thus, these bee products can be developed into potent apitherapeutic agents. However, some precautions need to be taken in case of allergens associated with bee products and in finding the right intake dosage. Hence, it is necessary to conduct further studies to determine the critical mechanisms related to the pharmacological activities of these bee products and the appropriate amounts that can be taken in order to obtain promising health benefits.

\section{Conflicts of Interest}

The authors declare no conflicts of interest.

\section{Acknowledgments}

The authors acknowledge the financial supports from the Research Acculturation Collaborative Effort (RACE) (R/RACE/A07.00/01147A/ 001/2015/000237) and a research university team grant (RUT) (1001/PPSP/853005).

\section{References}

[1] P. C. Molan, "The role of honey in the management of wounds," Journal of Wound Care, vol. 8, no. 8, pp. 415-418, 1999.

[2] P. V. Rao, K. T. Krishnan, N. Salleh, and S. H. Gan, "Biological and therapeutic effects of honey produced by honey bees and stingless bees: a comparative review," Revista Brasileira de Farmacognosia, vol. 26, no. 5, pp. 657-664, 2016.

[3] P. M. Fratellone, F. Tsimis, and G. Fratellone, "Apitherapy products for medicinal use," Journal of Alternative and Complementary Medicine, vol. 22, no. 2, pp. 1020-1022, 2016.

[4] A. Ajibola, "Physico-Chemical and Physiological Values of Honey and Its Importance as a Functional Food," International Journal of Food Sciences and Nutrition, vol. 2, no. 6, pp. 1-9, 2015.

[5] J. M. Alvarez-Suarez, S. Tulipani, S. Romandini, E. Bertoli, and M. Battino, "Contribution of honey in nutrition and human health: a review," Mediterranean Journal of Nutrition and Metabolism, vol. 3, no. 1, pp. 15-23, 2010.

[6] S. Castaldo and F. Capasso, "Propolis, an old remedy used in modern medicine," Fitoterapia, vol. 73, Supplement 1, pp. S1-S6, 2002.

[7] A. Shehu, S. Ismail, M. A. K. Rohin, A. Harun, A. A. Aziz, and M. Haque, "Antifungal properties of Malaysian Tualang honey and stingless bee propolis against Candida albicans and Cryptococcus neoformans," Journal of Applied Pharmaceutical Science, vol. 6, no. 2, pp. 044-050, 2016.

[8] A. Buttstedt, R. F. Moritz, and S. Erler, "More than royal food-major royal jelly protein genes in sexuals and workers of the honeybee Apis mellifera," Frontiers in Zoology, vol. 10, no. 1, p. 1, 2013.

[9] M. Kamakura, "Royalactin induces queen differentiation in honeybees," Nature, vol. 473, no. 7348, pp. 478-483, 2011.

[10] F. Ferreres, C. García-Viguera, F. Tomás-Lorente, and F. A. Tomás-Barberán, "Hesperetin: a marker of the floral origin of citrus honey," Journal of the Science of Food and Agriculture, vol. 61, no. 1, pp. 121-123, 1993.
[11] M. Moniruzzaman, M. Khalil, S. Sulaiman, and S. Gan, "Advances in the analytical methods for determining the antioxidant properties of honey: a review," African Journal of Traditional, Complementary and Alternative Medicines, vol. 9, no. 1, pp. 36-42, 2012.

[12] A. Gómez-Caravaca, M. Gómez-Romero, D. Arráez-Román, A. Segura-Carretero, and A. Fernández-Gutiérrez, "Advances in the analysis of phenolic compounds in products derived from bees," Journal of Pharmaceutical and Biomedical Analysis, vol. 41, no. 4, pp. 1220-1234, 2006.

[13] S. Huang, C.-P. Zhang, K. Wang, G. Q. Li, and F.-L. Hu, "Recent advances in the chemical composition of propolis," Molecules, vol. 19, no. 12, pp. 19610-19632, 2014.

[14] N. Volpi, "Separation of flavonoids and phenolic acids from propolis by capillary zone electrophoresis," Electrophoresis, vol. 25, no. 12, pp. 1872-1878, 2004.

[15] M. Lotfy, "Biological activity of bee propolis in health and disease," Asian Pacific Journal of Cancer Prevention, vol. 7, no. 1, pp. 22-31, 2006.

[16] T. Nagai and R. Inoue, "Preparation and the functional properties of water extract and alkaline extract of royal jelly," Food Chemistry, vol. 84, no. 2, pp. 181-186, 2004.

[17] T. Sugiyama, K. Takahashi, and H. Mori, "Royal jelly acid, 10-hydroxy-trans-2-decenoic acid, as a modulator of the innate immune responses," Endocrine, Metabolic \& Immune Disorders-Drug Targets, vol. 12, no. 4, pp. 368-376, 2012.

[18] M. F. Ramadan and A. Al-Ghamdi, "Bioactive compounds and health-promoting properties of royal jelly: a review," Journal of Functional Foods, vol. 4, no. 1, pp. 39-52, 2012.

[19] F. Marın, M. Martinez, T. Uribesalgo, S. Castillo, and M. Frutos, "Changes in nutraceutical composition of lemon juices according to different industrial extraction systems," Food Chemistry, vol. 78, no. 3, pp. 319-324, 2002.

[20] M. Küçük, S. Kolaylı, Ş. Karaoğlu, E. Ulusoy, C. Baltacı, and F. Candan, "Biological activities and chemical composition of three honeys of different types from Anatolia," Food Chemistry, vol. 100, no. 2, pp. 526-534, 2007.

[21] H.-K. Biesalski, L. O. Dragsted, I. Elmadfa et al., "Bioactive compounds: definition and assessment of activity," Nutrition, vol. 25, no. 11, pp. 1202-1205, 2009.

[22] M. Viuda-Martos, Y. Ruiz-Navajas, J. Fernández-López, and J. A. Pérez-Álvarez, "Functional properties of honey, propolis, and royal jelly," Journal of Food Science, vol. 73, no. 9, pp. R117-R124, 2008.

[23] M. Khalil and S. Sulaiman, "The potential role of honey and its polyphenols in preventing heart disease: a review," African Journal of Traditional, Complementary and Alternative Medicines, vol. 7, no. 4, pp. 315-321, 2010.

[24] B. Esquivel and E. A. Flores, "A new neo-clerodane Diterpenoid from Salvia gesneraeflora (Labiatae)," Heterocycles, vol. 55, no. 3, p. 505, 2001.

[25] A. Salatino, É. W. Teixeira, and G. Negri, "Origin and chemical variation of Brazilian propolis," Evidence-Based Complementary and Alternative Medicine, vol. 2, no. 1, pp. 33-38, 2005.

[26] M. Cotoras, P. Castro, H. Vivanco, R. Melo, and L. Mendoza, "Farnesol induces apoptosis-like phenotype in the phytopathogenic fungus Botrytis cinerea," Mycologia, vol. 105, no. 1, pp. $28-33,2013$. 
[27] M. B. Abubakar, W. Z. Abdullah, S. A. Sulaiman, and A. B. Suen, "A review of molecular mechanisms of the antileukemic effects of phenolic compounds in honey," International Journal of Molecular Sciences, vol. 13, no. 11, pp. 15054-15073, 2012.

[28] H. Izuta, Y. Chikaraishi, M. Shimazawa, S. Mishima, and H. Hara, "10-Hydroxy-2-decenoic acid, a major fatty acid from royal jelly, inhibits VEGF-induced angiogenesis in human umbilical vein endothelial cells," Evidence-Based Complementary and Alternative Medicine, vol. 6, no. 4, pp. 489-494, 2009.

[29] Y. Lin, R. Shi, X. Wang, and H.-M. Shen, "Luteolin, a flavonoid with potential for cancer prevention and therapy," Current Cancer Drug Targets, vol. 8, no. 7, pp. 634646, 2008.

[30] M. Mijanur Rahman, S. H. Gan, and M. I. Khalil, "Neurological effects of honey: current and future prospects," EvidenceBased Complementary and Alternative Medicine, vol. 2014, Article ID 958721, 13 pages, 2014.

[31] A. Ajao, A. Idowu, and A. Obembe, "Comparative proximate and chemical analysis of feral and arti-ficially reared bee honey samples from two ecological zones in Nigeria," Journal of Environmental Conservation Research, vol. 1, no. 3, pp. 53-55, 2013.

[32] M. Kassim, M. Achoui, M. Mansor, and K. M. Yusoff, "The inhibitory effects of Gelam honey and its extracts on nitric oxide and prostaglandin E 2 in inflammatory tissues," Fitoterapia, vol. 81, no. 8, pp. 1196-1201, 2010.

[33] M. Badruzzaman Khan, M. Moshahid Khan, A. Khan et al., "Naringenin ameliorates Alzheimer's disease (AD)-type neurodegeneration with cognitive impairment (AD-TNDCI) caused by the intracerebroventricular-streptozotocin in rat model," Neurochemistry International, vol. 61, no. 7, pp. 1081-1093, 2012.

[34] A. A. Tahir, N. F. A. Sani, N. A. Murad, S. Makpol, W. Z. W. Ngah, and Y. A. M. Yusof, "Combined ginger extract \& Gelam honey modulate Ras/ERK and PI3K/AKT pathway genes in colon cancer HT29 cells," Nutrition Journal, vol. 14, no. 1, p. 1, 2015.

[35] D. Vauzour, G. Corona, and J. P. Spencer, "Caffeic acid, tyrosol and p-coumaric acid are potent inhibitors of 5-Scysteinyl-dopamine induced neurotoxicity," Archives of Biochemistry and Biophysics, vol. 501, no. 1, pp. 106-111, 2010.

[36] M. T. Mansouri, Y. Farbood, M. J. Sameri, A. Sarkaki, B. Naghizadeh, and M. Rafeirad, "Neuroprotective effects of oral gallic acid against oxidative stress induced by 6hydroxydopamine in rats," Food Chemistry, vol. 138, no. 2, pp. 1028-1033, 2013.

[37] P. C. Molan, "The evidence supporting the use of honey as a wound dressing," The International Journal of Lower Extremity Wounds, vol. 5, no. 1, pp. 40-54, 2006.

[38] C. T. Esmon, "Crosstalk between inflammation and thrombosis," Maturitas, vol. 47, no. 4, pp. 305-314, 2004.

[39] H. Vermeulen, D. Ubbink, A. Goossens, R. De Vos, and D. Legemate, "Systematic review of dressings and topical agents for surgical wounds healing by secondary intention," British Journal of Surgery, vol. 92, no. 6, pp. 665-672, 2005.

[40] M. Subrahmanyam, "A prospective randomised clinical and histological study of superficial burn wound healing with honey and silver sulfadiazine," Burns, vol. 24, no. 2, pp. 157-161, 1998.
[41] R. Cooper and D. Gray, The Control of Wound Malodour with Honey-Based Wound Dressings and Ointments, pp. 26-32, Wounds UK, Aberdeen, 2005.

[42] R. White and P. Molan, "A summary of published clinical research on honey in wound management," Honey: A modern wound management product, pp. 130-143, Wounds UK, Aberdeen, 2005.

[43] P. Molan, "Why honey is effective as a medicine: 2. The scientific explanation of its effects," Bee World, vol. 82, no. 1, pp. 22-40, 2001.

[44] S. Aminu, A. Hassan, and U. Babayo, "Another use of honey," Tropical Doctor, vol. 30, no. 4, pp. 250-251, 2000.

[45] N. S. Al-Waili, “Topical application of natural honey, beeswax and olive oil mixture for atopic dermatitis or psoriasis: partially controlled, single-blinded study," Complementary Therapies in Medicine, vol. 11, no. 4, pp. 226-234, 2003.

[46] V. Falanga, "Wound healing and its impairment in the diabetic foot," The Lancet, vol. 366, no. 9498, pp. 17361743, 2005.

[47] C. Dunford and R. Hanano, "Acceptability to patients of a honey dressing for non-healing venous leg ulcers," Journal of Wound Care, vol. 13, no. 5, pp. 193-198, 2004.

[48] H. Mohamed, M. A. Salma, B. Al Lenjawi et al., "Enhancing primary healing post ray amputation in a diabetic patient: efficacy of natural honey," Journal of Diabetic Foot Complications, vol. 6, no. 1, pp. 13-18, 2014.

[49] A. Ajibola, J. P. Chamunorwa, and K. H. Erlwanger, "Nutraceutical values of natural honey and its contribution to human health and wealth," Nutrition \& Metabolism, vol. 9, no. 1, p. 61, 2012.

[50] T. Adebolu, "Effect of natural honey on local isolates of diarrhea-causing bacteria in southwestern Nigeria," African Journal of Biotechnology, vol. 4, no. 10, p. 1172, 2005.

[51] M. A. Abeshu and B. Geleta, "Medicinal uses of honey," Biology and Medicine, vol. 8, no. 2, pp. 1-7, 2016.

[52] S. Kajiwara, H. Gandhi, and Z. Ustunol, "Effect of honey on the growth of and acid production by human intestinal Bifidobacterium spp.: an in vitro comparison with commercial oligosaccharides and inulin," Journal of Food Protection ${ }^{\circledR}$, vol. 65, no. 1, pp. 214-218, 2002.

[53] T. Shamala, Y. Shri Jyothi, and P. Saibaba, "Stimulatory effect of honey on multiplication of lactic acid bacteria under in vitro and in vivo conditions," Letters in Applied Microbiology, vol. 30, no. 6, pp. 453-455, 2000.

[54] H. R. Cardarelli, F. C. Buriti, I. A. Castro, and S. M. Saad, "Inulin and oligofructose improve sensory quality and increase the probiotic viable count in potentially synbiotic petit-suisse cheese," LWT-Food Science and Technology, vol. 41, no. 6, pp. 1037-1046, 2008.

[55] C. Anyanechi and B. Saheeb, "Honey and wound dehiscence: a study of surgical wounds in the mandibular bed," Nigerian Journal of Clinical Practice, vol. 18, no. 2, pp. 251-255, 2015.

[56] S. Eick, G. Schäfer, J. Kwiecinski, J. Atrott, T. Henle, and W. Pfister, "Honey-a potential agent against Porphyromonas gingivalis: an in vitro study," BMC Oral Health, vol. 14, no. 1, p. 24, 2014.

[57] D. S. Halim, E. S. Mahanani, R. Saini, M. Omar, N. Rubiantee bt Ibrahi, and M. K. Alam, "A comparison study on the effectiveness of local honey and salicylate gel for treatment of minor recurrent aphtous stomatitis," International Medical Journal, vol. 20, no. 6, pp. 770-772, 2013. 
[58] J. J. Song, P. Twumasi-Ankrah, and R. Salcido, "Systematic review and meta-analysis on the use of honey to protect from the effects of radiation-induced oral mucositis," Advances in Skin \& Wound Care, vol. 25, no. 1, pp. 23-28, 2012.

[59] N. Sterer and M. Rosenberg, Breath Odors: Origin, Diagnosis, and Management, Springer Science \& Business Media, 2011.

[60] H. Shiga, A. Jo, K. Terao, M. Nakano, T. Oshima, and N. Maeda, "Decrease of halitosis by intake of Manuka honey," General Session of IADR Barcelona, vol. 14, 2010.

[61] D. E. Bessen, "Tissue tropisms in group A Streptococcus: what virulence factors distinguish pharyngitis from impetigo strains?" Current Opinion in Infectious Diseases, vol. 29, no. 3, pp. 295-303, 2016.

[62] R. K. Gupta and S. Stangaciu, "Apitherapy: holistic healing through the honeybee and bee products in countries with poor healthcare system," in Beekeeping for Poverty Alleviation and Livelihood Security, pp. 413-446, Springer, 2014.

[63] S. Patel and S. Cichello, "Manuka honey: an emerging natural food with medicinal use," Natural Products and Bioprospecting, vol. 3, no. 4, pp. 121-128, 2013.

[64] M. N. Shadkam, H. Mozaffari-Khosravi, and M. R. Mozayan, "A comparison of the effect of honey, dextromethorphan, and diphenhydramine on nightly cough and sleep quality in children and their parents," The Journal of Alternative and Complementary Medicine, vol. 16, no. 7, pp. 787-793, 2010.

[65] K. N. Memon, K. Shaikh, B. S. Pandhiani, and G. Usman, "How do mothers recognize \& treat pneumonia in their children at home? A study in union council Jhudo, District Mirpurkhas," Journal of Liaquat University of Medical \& Health Sciences, vol. 12, no. 03, p. 208, 2013.

[66] F. Abdellah and L. A. Abderrahim, "8 honey for gastrointestinal," in Honey in Traditional and Modern Medicine, p. 159, CRC Press, Boca raton, Florida, USA, 2013.

[67] E. Header, A. E.-M. Hashish, N. ElSawy, A. Al-Kushi, and M. El-Boshy, "Gastroprotective effects of dietary honey against acetylsalicylate induced experimental gastric ulcer in albino rats," Life Science Journal, vol. 13, no. 1, 2016.

[68] A. Lychkova, V. Kasyanenko, and A. Puzikov, "Gastroprotective effect of honey and bee pollen," Experimental \& Clinical Gastroenterology, vol. 9, p. 72, 2014.

[69] E. Halligan, J. Edgeworth, K. Bisnauthsing et al., "Multiplex molecular testing for management of infectious gastroenteritis in a hospital setting: a comparative diagnostic and clinical utility study," Clinical Microbiology and Infection, vol. 20, no. 8, pp. O460-O467, 2014.

[70] M. A. Abdulrhman, M. A. Mekawy, M. M. Awadalla, and A. H. Mohamed, "Bee honey added to the oral rehydration solution in treatment of gastroenteritis in infants and children," Journal of Medicinal Food, vol. 13, no. 3, pp. 605-609, 2010.

[71] L. J. Brandt, C. M. Prather, E. M. Quigley, L. R. Schiller, P. Schoenfeld, and N. J. Talley, "Systematic review on the management of chronic constipation in North America," The American Journal of Gastroenterology, vol. 100, no. S1, pp. S5-S21, 2005.

[72] B. Andualem, "Synergistic antimicrobial effect of Tenegn honey (Trigona iridipennis) and garlic against standard and clinical pathogenic bacterial isolates," International Journal of Microbiology Research, vol. 4, no. 1, pp. 16-22, 2013.
[73] S. Zhang, T. Jiao, Y. Chen, N. Gao, L. Zhang, and M. Jiang, "Methylglyoxal induces systemic symptoms of irritable bowel syndrome," PLoS One, vol. 9, no. 8, article e105307, 2014.

[74] Y. Wang, D. Li, N. Cheng et al., "Antioxidant and hepatoprotective activity of Vitex honey against paracetamol induced liver damage in mice," Food \& Function, vol. 6, no. 7, pp. 2339-2349, 2015.

[75] O. Erejuwa, S. Sulaiman, M. Wahab, K. Sirajudeen, M. M. Salleh, and S. Gurtu, "Antioxidant protection of Malaysian Tualang honey in pancreas of normal and streptozotocininduced diabetic rats," in Annales d'endocrinologie, pp. 291296, Elsevier, 2010.

[76] O. O. Erejuwa, S. A. Sulaiman, M. Wahab, K. Sirajudeen, M. Salleh, and S. Gurtu, "Glibenclamide or metformin combined with honey improves glycemic control in streptozotocininduced diabetic rats," International Journal of Biological Sciences, vol. 7, no. 2, pp. 244-252, 2011.

[77] M. K. Rakha, Z. I. Nabil, and A. A. Hussein, "Cardioactive and vasoactive effects of natural wild honey against cardiac malperformance induced by hyperadrenergic activity," Journal of Medicinal Food, vol. 11, no. 1, pp. 91-98, 2008.

[78] R. Afroz, E. Tanvir, N. Karim et al., "Sundarban honey confers protection against isoproterenol-induced myocardial infarction in Wistar rats," BioMed Research International, vol. 2016, Article ID 6437641, 10 pages, 2016.

[79] M. Khalil, S. Sulaiman, and L. Boukraa, "Antioxidant properties of honey and its role in preventing health disorder," The Open Nutraceuticals Journal, vol. 3, no. 1, pp. 6-16, 2010.

[80] A. Ajibola, "Growth and metabolic response of suckling rats fed with natural honey supplements," Ommega Internations, vol. 3, no. 1, pp. 1-8, 2016.

[81] J. B. Daleprane, V. da Silva Freitas, A. Pacheco et al., "Antiatherogenic and anti-angiogenic activities of polyphenols from propolis," The Journal of Nutritional Biochemistry, vol. 23, no. 6, pp. 557-566, 2012.

[82] S. Bogdanov, T. Jurendic, R. Sieber, and P. Gallmann, "Honey for nutrition and health: a review," Journal of the American College of Nutrition, vol. 27, no. 6, pp. 677-689, 2008.

[83] D. Germain, "Estrogen carcinogenesis in breast cancer," Endocrinology and Metabolism Clinics of North America, vol. 40, no. 3, pp. 473-484, 2011.

[84] O. O. Erejuwa, S. A. Sulaiman, and M. S. A. Wahab, "Effects of honey and its mechanisms of action on the development and progression of cancer," Molecules, vol. 19, no. 2, pp. 2497-2522, 2014.

[85] A. V. Tsiapara, M. Jaakkola, I. Chinou et al., "Bioactivity of Greek honey extracts on breast cancer (MCF-7), prostate cancer (PC-3) and endometrial cancer (Ishikawa) cells: profile analysis of extracts," Food Chemistry, vol. 116, no. 3, pp. 702-708, 2009.

[86] A. N. Fauzi, M. N. Norazmi, and N. S. Yaacob, “Tualang honey induces apoptosis and disrupts the mitochondrial membrane potential of human breast and cervical cancer cell lines," Food and Chemical Toxicology, vol. 49, no. 4, pp. 871878, 2011.

[87] A. Abdel Aziz, H. Rady, M. Amer, and H. Kiwan, "Effect of some honey bee extracts on the proliferation, proteolytic and gelatinolytic activities of the hepatocellular carcinoma Hepg2 cell line," Australian Journal of Basic and Applied Sciences, vol. 3, no. 3, pp. 2754-2769, 2009. 
[88] C. T. P. Wen, S. Z. Hussein, S. Abdullah, N. A. Karim, S. Makpol, and Y. A. M. Yusof, "Gelam and Nenas honeys inhibit proliferation of HT 29 colon cancer cells by inducing DNA damage and apoptosis while suppressing inflammation," Asian Pacific Journal of Cancer Prevention, vol. 13, no. 4, pp. 1605-1610, 2012.

[89] S. Jaganathan and M. Mandal, "Honey constituents and its apoptotic effect in colon cancer cells," Journal of Apiproduct and Apimedical Science, vol. 1, no. 2, pp. 29-36, 2009.

[90] S. Ahmed and N. H. Othman, "Honey as a potential natural anticancer agent: a review of its mechanisms," EvidenceBased Complementary and Alternative Medicine, vol. 2013, Article ID 829070, 7 pages, 2013.

[91] S. Freitas, L. Shinohara, J. Sforcin, and S. Guimarães, "In vitro effects of propolis on Giardia duodenalis trophozoites," Phytomedicine, vol. 13, no. 3, pp. 170-175, 2006.

[92] N. Paulino, L. A. Coutinho, J. R. Coutinho, G. C. Vilela, V. P. da Silva Leandro, and A. S. Paulino, "Antiulcerogenic effect of Brazilian propolis formulation in mice," Pharmacology \& Pharmacy, vol. 6, no. 12, p. 580, 2015.

[93] M. Imhof, M. Lipovac, C. Kurz, J. Barta, H. C. Verhoeven, and J. C. Huber, "Propolis solution for the treatment of chronic vaginitis," International Journal of Gynaecology and Obstetrics, vol. 89, no. 2, pp. 127-132, 2005.

[94] I. R. G. Capoci, S. Bonfim-Mendonça Pde, G. S. Arita et al., "Propolis is an efficient fungicide and inhibitor of biofilm production by vaginal Candida albicans," EvidenceBased Complementary and Alternative Medicine, vol. 2015, Article ID 287693, 9 pages, 2015.

[95] E. M. R. Pereira, J. L. D. C. da Silva, F. F. Silva, M. P. De Luca, T. C. M. Lorentz, and V. R. Santos, "Clinical evidence of the efficacy of a mouthwash containing propolis for the control of plaque and gingivitis: a phase II study," Evidence-Based Complementary and Alternative Medicine, vol. 2011, Article ID 750249, 7 pages, 2011.

[96] S. Jain, R. Rai, V. Sharma, and M. Batra, "Propolis in oral health: a natural remedy," World Journal of Pharmaceutical Sciences, vol. 2, no. 1, pp. 90-94, 2014.

[97] P. F. R. Bertolini, O. Biondi Filho, A. Pomilio, S. L. Pinheiro, and M. S. D. Carvalho, "Antimicrobial capacity of Aloe vera and propolis dentifrice against Streptococcus mutans strains in toothbrushes: an in vitro study," Journal of Applied Oral Science, vol. 20, no. 1, pp. 32-37, 2012.

[98] D. Skaba, T. Morawiec, M. Tanasiewicz et al., "Influence of the toothpaste with Brazilian ethanol extract propolis on the oral cavity health," Evidence-Based Complementary and Alternative Medicine, vol. 2013, Article ID 215391, 12 pages, 2013.

[99] H. Xuan, Z. Li, H. Yan et al., "Antitumor activity of Chinese propolis in human breast cancer MCF-7 and MDA-MB-231 cells," Evidence-Based Complementary and Alternative Medicine, vol. 2014, Article ID 280120, 11 pages, 2014.

[100] L. Benguedouar, M. Lahouel, S. Gangloff et al., “Algerian ethanolic extract of propolis and galangin decreased melanoma tumour progression in C57BL6 mice," in Annales de Dermatologie et de Vénéréologie, p. S294, Elsevier, France, 2015.

[101] S. Demir, Y. Aliyazicioglu, I. Turan et al., "Antiproliferative and proapoptotic activity of Turkish propolis on human lung cancer cell line," Nutrition and Cancer, vol. 68, no. 1, pp. 165-172, 2016.
[102] B. M. M. Ali, N. F. Ghoname, A. A. Hodeib, and M. A. Elbadawy, "Significance of topical propolis in the treatment of facial acne vulgaris," Egyptian Journal of Dermatology and Venerology, vol. 35, no. 1, p. 29, 2015.

[103] P. Olczyk, K. Komosinska-Vassev, G. Wisowski, L. Mencner, J. Stojko, and E. M. Kozma, "Propolis modulates fibronectin expression in the matrix of thermal injury," BioMed Research International, vol. 2014, Article ID 748101, 10 pages, 2014.

[104] F. R. Henshaw, T. Bolton, V. Nube et al., "Topical application of the bee hive protectant propolis is well tolerated and improves human diabetic foot ulcer healing in a prospective feasibility study," Journal of Diabetes and Its Complications, vol. 28, no. 6, pp. 850-857, 2014.

[105] S. Taavoni, F. Barkhordari, A. Goushegir, and H. Haghani, "Effect of royal jelly on premenstrual syndrome among Iranian medical sciences students: a randomized, tripleblind, placebo-controlled study," Complementary Therapies in Medicine, vol. 22, no. 4, pp. 601-606, 2014.

[106] F. Seyyedi, M. Rafiean-Kopaei, and S. Miraj, "Comparison of the effects of vaginal royal jelly and vaginal estrogen on quality of life, sexual and urinary function in postmenopausal women," Journal of Clinical and Diagnostic Research, vol. 10, no. 5, article QC01, 2016.

[107] G. Najafi, V. Nejati, A. Shalizar Jalali, and E. Zahmatkesh, "Protective role of royal jelly in oxymetholone-induced oxidative injury in mouse testis," Iranian Journal of Toxicology, vol. 8, no. 25, pp. 1073-1080, 2014.

[108] A. El-Hanoun, A. Elkomy, W. Fares, and E. Shahien, "Impact of royal jelly to improve reproductive performance of male rabbits under hot summer conditions," World Rabbit Science, vol. 22, no. 3, pp. 241-248, 2014.

[109] M. Imai, A. Umezawa, J. Qin, K. Miyado, N. Yamakawa, and Y. Takahashi, "Molecular Alterations during Female Reproductive Aging: Can Aged Oocytes Remind Youth?" in INTECH Open Access Publisher, Croatia, 2012.

[110] Z. Zamani, P. Reisi, H. Alaei, and A. A. Pilehvarian, "Effect of royal jelly on spatial learning and memory in rat model of streptozotocin-induced sporadic Alzheimer's disease," Advanced Biomedical Research, vol. 1, no. 2, pp. 1-6, 2012.

[111] Y. Honda, Y. Fujita, H. Maruyama et al., "Lifespan-extending effects of royal jelly and its related substances on the nematode Caenorhabditis elegans," PloS One, vol. 6, no. 8, article e23527, 2011.

[112] H. Morita, T. Ikeda, K. Kajita et al., "Effect of royal jelly ingestion for six months on healthy volunteers," Nutrition Journal, vol. 11, no. 1, p. 77, 2012.

[113] J. Kim, Y. Kim, H. Yun et al., "Royal jelly enhances migration of human dermal fibroblasts and alters the levels of cholesterol and sphinganine in an in vitro wound healing model," Nutrition Research and Practice, vol. 4, no. 5, pp. 362-368, 2010.

[114] H. M. Park, E. Hwang, K. G. Lee, S.-M. Han, Y. Cho, and S. Y. Kim, "Royal jelly protects against ultraviolet B-induced photoaging in human skin fibroblasts via enhancing collagen production," Journal of Medicinal Food, vol. 14, no. 9, pp. 899-906, 2011.

[115] M. Siavash, S. Shokri, S. Haghighi, M. A. Shahtalebi, and Z. Farajzadehgan, "The efficacy of topical royal jelly on healing of diabetic foot ulcers: a double-blind placebo-controlled clinical trial," International Wound Journal, vol. 12, no. 2, pp. 137-142, 2015. 


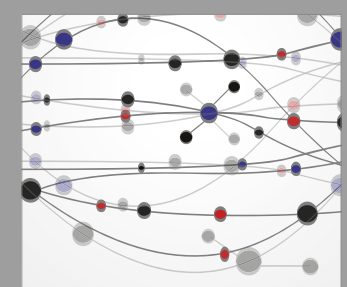

The Scientific World Journal
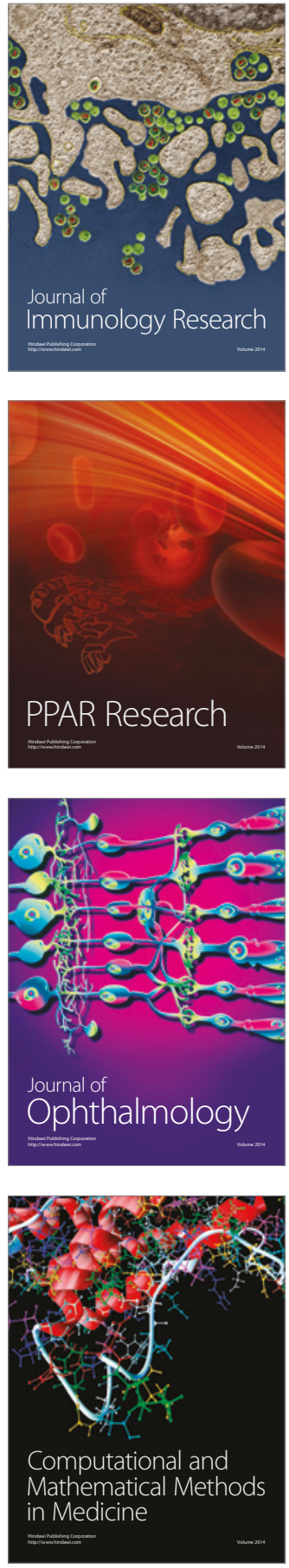

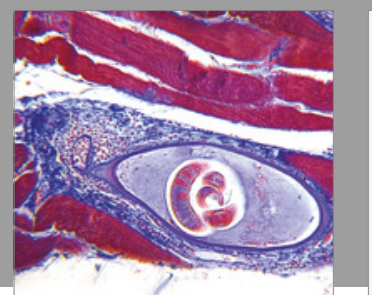

Gastroenterology Research and Practice
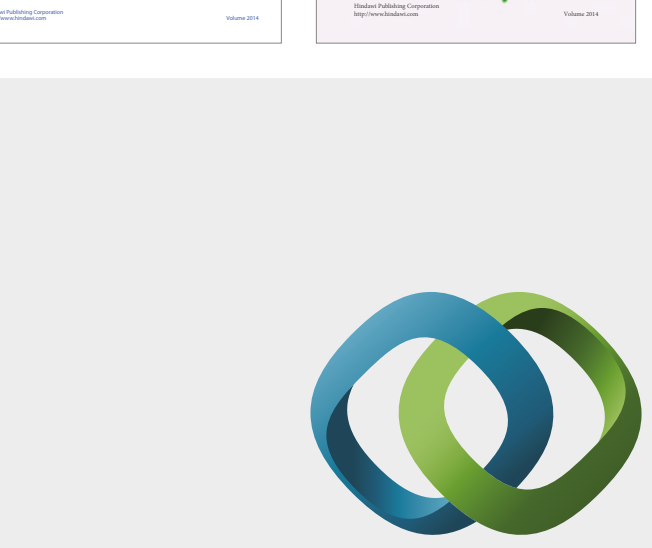

\section{Hindawi}

Submit your manuscripts at

https://www.hindawi.com
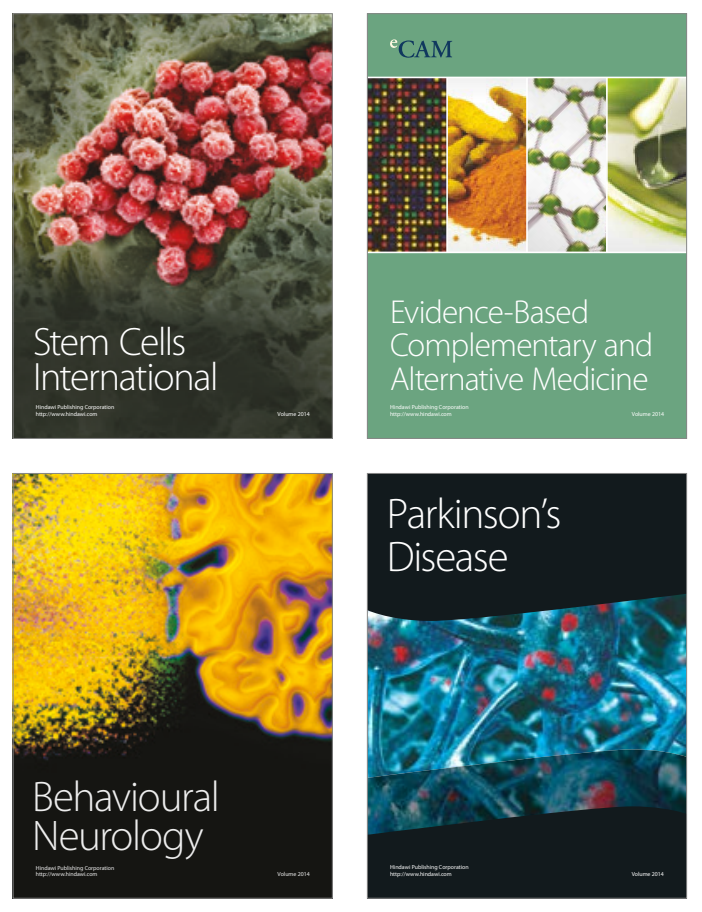
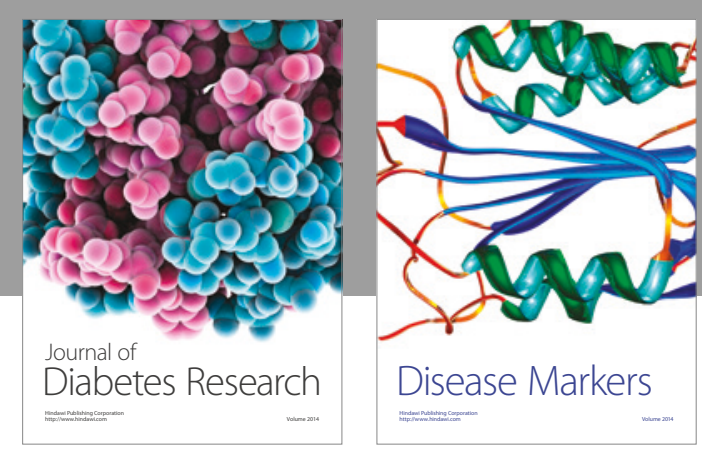

Disease Markers
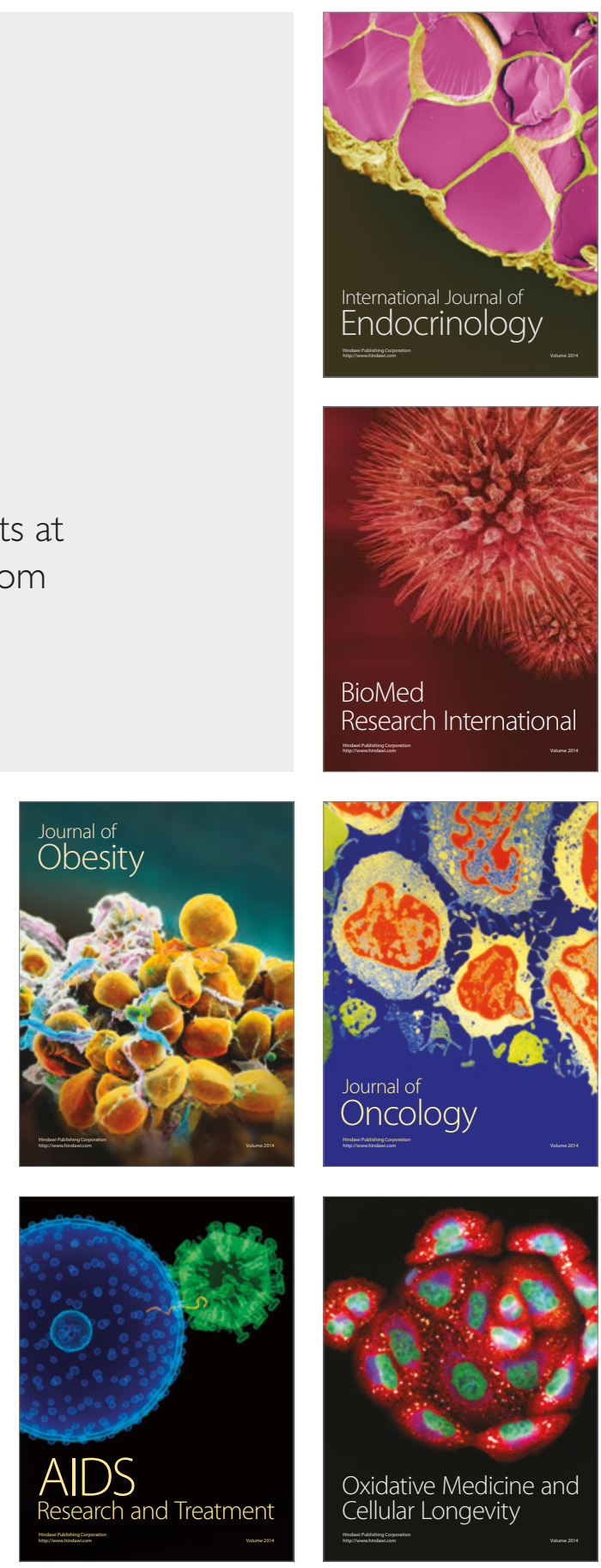